\title{
Renata Ferrari
}

EVOLUÇÃO DOS MARCADORES DIAGNÓSTICOS E PROGNÓSTICOS DE PACIENTES COM DPOC NO PERÍODO DE TRÊS ANOS 


\title{
Renata Ferrari
}

\section{EVOLUÇÃO DOS MARCADORES DIAGNÓSTICOS E PROGNÓSTICOS DE PACIENTES COM DPOC NO PERÍODO DE TRÊS ANOS}

\author{
Dissertação de Mestrado apresentada Ao \\ Programa de Pós-Graduação "Fisiopatologia \\ em Clínica Médica” da Faculdade de Medicina \\ de Botucatu - UNESP, como pré-requisito para \\ obtenção do título de Mestre
}

Orientadora: Prof ${ }^{a}$ Adjunta Irma de Godoy

Bolsa FAPESP - Mestrado (Processo 2008/52667-0)

Botucatu 
FICHA CATALOGRÁFICA ELABORADA PELA SEÇÃO TÉCNICA DE AQUISIÇÃO E TRATAMENTO DA INFORMAÇÃO

DIVISÃO TÉCNICA DE BIBLIOTECA E DOCUMENTAÇÃO - CAMPUS DE BOTUCATU - UNESP BIBLIOTECÁRIA RESPONSÁVEL: Selma Maria de Jesus

\section{Ferrari, Renata.}

Evolução dos marcadores diagnósticos e prognósticos de pacientes com DPOC no período de três anos / Renata Ferrari. - Botucatu, 2010.

Dissertação (mestrado) - Faculdade de Medicina de Botucatu, Universidade Estadual Paulista, 2010

Orientador: Irma de Godoy

Assunto CAPES: 40105008

1. Doença pulmonar obstrutiva crônica

Palavras-chave: Doença pulmonar obstrutiva crônica; Índice de gravidade da doença; Mortalidade; Prognóstico; Qualidade de vida 


\section{Dedícatóría}

Dedíco essa dissertação aos meus país, exemplos de esforço e persistência, que servem de suporte para minha vida profíssional.

Dedico também ao Eduardo. Seu amor, companheirismo e cumplicidade me guiaram durante cada etapa deste trabalho. 


\section{Agradecimento Especial}

Agradeço à Profa Irma de Godoy pela confiança, pelos direcionamentos e principalmente por dar liberdade para a conquista de novos conhecimentos. Seu profíssionalismo e dedicação servirão sempre para conduzir minhas atitudes. 


\section{Agradecimentos}

Aos pacientes que gentílmente aceitaram participar desta pesquisa.

Aos meus familiares que sempre estiveram presentes e me incentivaram. Especialmente ao primo Robson pelo exemplo de amor à pesquisa.

Aos amigos do grupo de pesquisa: Daniela, ICda, Karina, Laura, Mariana, Paulo, Renata, Rosana, Suzana. Obrígada pela ajuda na coleta de dados, pela companhía nos congressos e pelo apoio no dia-adía.

À Suzana pelo seu envolvimento na pesquisa e execução das avaliações médicas e da estatística. Obrigada pelos ensinamentos e pela ajuda de sempre.

Ao Prof. Fábio Pitta pela confiança dedicada desde a graduação.

Ȧ Prof $^{a}$ Larissa Belinetti pela oportunidade de engajamento na pesquisa durante minha graduação.

Ao Prof. Sérgio pela ajuda com os gráficos e com a estatística.

Às funcionárias da função pulmonar: Lurdinha, Lucía e Mary pela atenção com os pacientes e pela ajuda no aprimoramento da execução da espirometría.

Aos funcionários da Pós-Graduação da Faculdade de Medicina de Botucatu pela paciência e dedicação.

Aos funcionários do Departamento de Clinica Médica pela disponibilidade e auxilio operacional. 


\section{Epígrafe}

"Por mais objetiva que os cientistas pretendam que a ciência seja, a interpretação dos dados sempre envolve algo mágico... criativo...um imaterial que ordena e dispersa o caos. É nesta etapa da pesquisa que procuramos entender uma faceta da natureza... o colorido de um conjunto caótico de números e fatos. Sem ela, somos apenas coletores de dados... mas não cientista."

Gilson Volpato 


\section{RESUMO}

Estudos mostram a evolução dos marcadores locais e sistêmicos da doença pulmonar obstrutiva crônica (DPOC) e sua associação com o prognóstico da doença. No entanto, não identificamos estudos prévios avaliando a evolução desses marcadores em pacientes brasileiros com DPOC. Além disso, a associação entre as modificações dos marcadores da doença e a qualidade de vida relacionada à saúde não está clara. O objetivo deste estudo foi verificar a evolução dos marcadores diagnósticos e prognósticos de pacientes com DPOC e a associação destes marcadores com a mortalidade, exacerbação e modificações na qualidade de vida relacionada à saúde no período de três anos. No momento basal foram avaliados 133 pacientes com DPOC leve a muito grave, 15 pacientes (11\%) morreram durante o seguimento e 23 pacientes (17\%) não foram reavaliados. Portanto, 95 pacientes $(72 \%)$ foram submetidos às seguintes avaliações no momento basal e após três anos: espirometria, composição corporal, sensação da dispneia por meio da escala Medical Research Council (MRC) e do índice de dispneia basal (BDI), qualidade de vida por meio do Questionário do Hospital Saint George na Doença Respiratória (SGRQ), comorbidades (Índice Charlson), tolerância ao exercício (distância percorrida em seis minutos-DP6) e cálculo do Índice BODE. Após a avaliação inicial, os pacientes ou seus familiares foram contatados a cada três meses para verificar a frequência de exacerbações e óbito. A evolução dos marcadores foi feita por meio do teste "T" para medidas repetidas. Análise de regressão de Cox foi realizada para identificar os preditores de mortalidade. A associação dos marcadores da doença com a frequência de exacerbação foi avaliada por meio da análise de regressão de Poisson. Análise de regressão logística foi utilizada para avaliar os preditores de melhora ou piora da qualidade de vida relacionada à saúde. Após três anos de estudo, não houve alteração nos valores do $\mathrm{VEF}_{1}$ $(\mathrm{p}=0,23)$ e do IMC ( $\mathrm{p}=0,38)$. Houve piora significativa da DP6, da $\mathrm{SpO}_{2}$, do MRC, do BDI, do Índice Charlson e do Índice BODE quando comparados ao momento basal. Houve também piora do domínio atividade $(52 \pm 21$ vs $60 \pm 22 \%$; p<0,001) e do escore total $(42 \pm 19$ vs $44 \pm 19 \%$; p=0,041) do SGRQ. O aumento na idade e no índice BODE foram preditores de mortalidade. As variáveis associadas com a exacerbação foram o Índice $\mathrm{BODE}$ e a $\mathrm{SpO}_{2}$. A variação do índice BODE foi preditora da piora clinicamente significativa da qualidade de vida. Em conclusão, nosso estudo trouxe uma contribuição inédita na literatura referente à associação entre as alterações do índice BODE e da qualidade de vida relacionada à saúde e identificou que achados previamente descritos em estudos internacionais são válidos para a população brasileira. 
Palavras-chave: Doença Pulmonar Obstrutiva Crônica, Índice de gravidade da doença, mortalidade, prognóstico e qualidade de vida. 


\begin{abstract}
Studies show the evolution of local and systemic markers of chronic obstructive pulmonary disease (COPD) and its association with the disease prognosis. However, we did not identify previous studies evaluating the evolution of these markers in Brazilian patients with COPD. In addition, the association between modifications in disease markers and health-related quality of life (HRQL) are unclear. The objective of this study was to verify the evolution of diagnostic and prognostic markers in COPD patients and the association of these markers with mortality, exacerbation and modifications in HRQL over three years. At baseline were evaluated 133 patients with mild to very severe COPD, 15 patients $(11 \%)$ died and 23 patients (17\%) dropped out during the follow-up period. Therefore, 95 patients (72\%) underwent following the evaluations at baseline and after three years: spirometry, body composition, dyspnea perception using the Medical Research Council scale (MRC) and the baseline dyspnea index (BDI), quality of life questionnaire by Saint George's Respiratory Questionnaire (SGRQ), comorbidities (Charlson index), exercise tolerance (six-minute walk distance-6MWD) and the calculate BODE index. After the initial assessment, patients or their relatives were contacted every three months to verify the exacerbations frequency and death. The evolution of the markers was evaluated using the paired t-test. Cox regression analysis was performed to identify mortality predictors. Association of disease markers with exacerbation frequency was assessed by Poisson regression analysis. Logistic regression analysis was used to evaluate the predictors of improvement or worsening of HRQL. After three years of study, there was no change in the values of $\mathrm{FEV}_{1}(\mathrm{p}=0.23)$ and BMI $(\mathrm{p}=0.38)$. There was a significant worsening of $6 \mathrm{MWD}, \mathrm{SpO}_{2}, \mathrm{MRC}$, BDI, Charlson index and BODE index when compared to baseline. There was also worsening domain activity $(52 \pm 21 \mathrm{vs}$ $60 \pm 22 \%, \mathrm{p}<0.001)$ and total score $(42 \pm 19$ vs $44 \pm 19 \%, \mathrm{p}=0.041)$ of the SGRQ. The increase in the age and in the BODE index were mortality predictors. The variables associated with exacerbation were BODE Index and $\mathrm{SpO}_{2}$. BODE index variation was a predictor of clinically significant worsening of HRQL. In conclusion, our study has provided an unprecedented contribution to the literature on the association between modifications in the BODE index and HRQL and identified that previously described findings in international studies are valid for the Brazilian population.
\end{abstract}

Key words: Chronic Obstructive Pulmonary Disease, severity of illness index, mortality, prognosis, quality of life. 


\section{LISTA DE ABREVIATURAS}

ATS: American Thoracic Society

BDI: Índice de dispneia basal

BODE: Body mass index, Obstruction, Dyspnea, Exercise

CEP: Comitê de Ética e Pesquisa

CVF: Capacidade vital forçada

DP6: Distância percorrida em seis minutos

DPOC: Doença Pulmonar Obstrutiva Crônica

GOLD: Global Initiative for Chronic Obstrutive Lung Disease

ICC: Insuficiência Cardíaca Congestiva

IMC: Índice de massa do corpo

IMMC: Índice de massa magra do corpo

MMC: Massa magra do corpo

MRC: Medical Research Council

ODP: Oxigenoterapia domiciliar prolongada

OMS: Organização Mundial de Saúde

$\mathrm{PaCO}_{2}$ : Pressão arterial de oxigênio

$\mathrm{PaO}_{2}$ : Pressão arterial de gás carbônico

SGRQ: Saint George's Respiratory Questionnaire

$\mathrm{SpO}_{2}$ : Oximetria pulso

TDI: Transition Dyspnea Index

$\mathrm{VEF}_{1:}$ Volume expiratório forçado no primeiro segundo 


\section{SUMÁRIO}

Resumo

Abstract

Lista de Abreviaturas

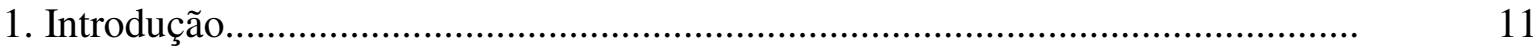

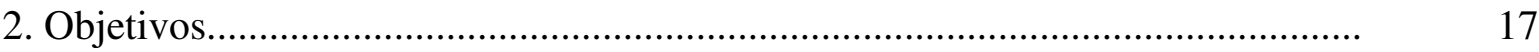

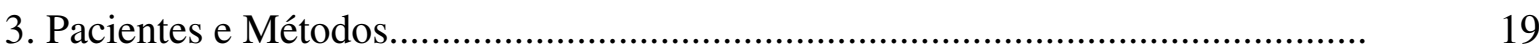

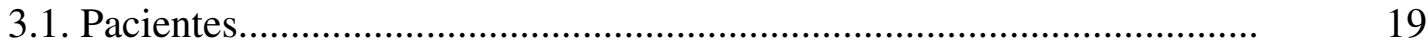

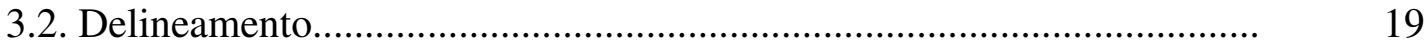

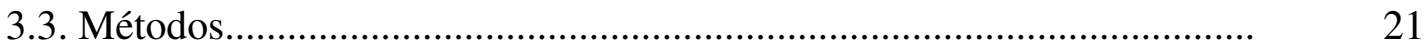

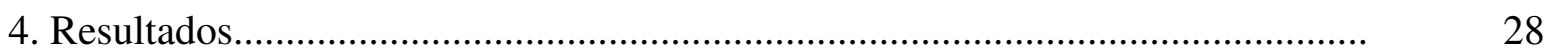

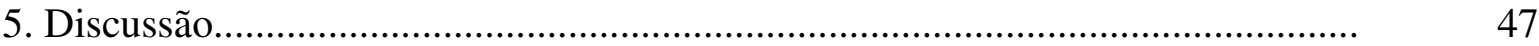

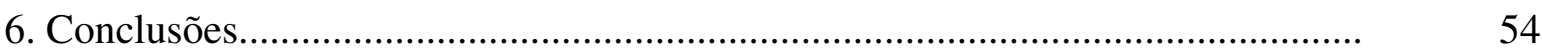

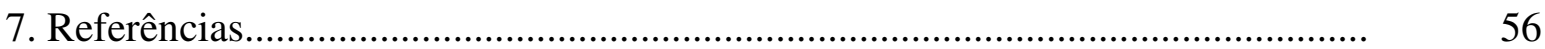

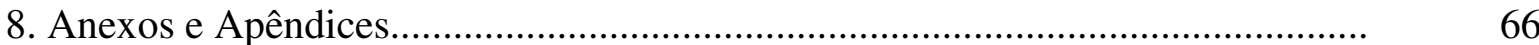


Introdução 


\section{INTRODUÇÃO}

A doença pulmonar obstrutiva crônica (DPOC) é uma das principais causas de morbidade e mortalidade e a condição respiratória crônica mais comum no mundo desenvolvido (Fabbri et al., 2006). Está associada com diminuição da capacidade ou incapacidade para o trabalho, mortalidade prematura e, assim, tem importantes repercussões econômicas (Fabbri et al., 2006).

A prevalência real da DPOC, no mundo e no Brasil, não é conhecida. É a quarta causa de morte nos EUA e estima-se que aproximadamente 16 milhões de americanos apresentam DPOC sintomática (Fabbri et al., 2006). Estimativas da Organização Mundial de Saúde mostram que a mortalidade associada à DPOC pode aumentar aproximadamente $30 \%$ nos próximos dez anos e que, em 2030, a doença será a terceira causa de morte no mundo (WHO, 2009).

No Brasil, estudo realizado na região metropolitana da cidade de São Paulo indicou que 15,8\% dos indivíduos maiores que 40 anos apresentam DPOC. A prevalência é maior em homens e aumenta acentuadamente com a idade (Menezes et al., 2005). Segundo dados do DATASUS (2008), a doença ocupa o quinto lugar dentre as principais causas de morte e o número de óbitos consequentes a ela, em ambos os sexos, vem aumentando nos últimos 20 anos (Jardim et al., 2004).

A DPOC é caracterizada pelo desenvolvimento progressivo de limitação ao fluxo aéreo que não é totalmente reversível. Esta limitação está associada à resposta inflamatória anormal dos pulmões a partículas e gases nocivos, principalmente o tabagismo (Fabbri et al., 2006). Valores de volume expiratório forçado no primeiro segundo ( $\left.\mathrm{VEF}_{1}\right)$, pósbroncodilatador, expressos como porcentagem da capacidade vital forçada (CVF) $\left(\mathrm{VEF}_{1} / \mathrm{CVF}\right)<70 \%$, indicam a presença da doença. A gravidade da obstrução é estabelecida por meio da análise dos resultados de $\mathrm{VEF}_{1}$, expressos como porcentagem dos valores previstos de acordo com a Global Initiative for Chronic Obstrutive Lung Disease (GOLD) (Fabbri et al., 2006) e pelo II Consenso Brasileiro de DPOC (Jardim, Oliveira et al., 2004). Pacientes com $\mathrm{VEF}_{1} \geq 80 \%$ do valor previsto são classificados como portadores da doença em estádio I, valores de $\mathrm{VEF}_{1} \geq 50 \%$ e $<80 \%$ do previsto caracterizam o estádio II e, $\mathrm{VEF}_{1} \geq$ $30 \%$ e $<50 \%$ do previsto o estádio III. São considerados portadores de doença em estádio IV os pacientes que apresentam $\mathrm{VEF}_{1}<30 \%$ do previsto ou $\mathrm{VEF}_{1}<50 \%$ do previsto associado à insuficiência respiratória crônica. 
A evolução crônica e progressiva da DPOC é caracterizada por episódios de exacerbação da doença que ocorrem pelo menos duas vezes ao ano em pacientes com doença moderada/grave (Miravitlles et al., 1999). A exacerbação é definida como piora de início agudo e sustentada dos sintomas da doença, maior que a oscilação diária característica, que resulta em alteração da dose ou da medicação de manutenção utilizada (Rodriguez-Roisin, 2000). Os três sintomas principais são piora da dispneia, aumento do volume e aparecimento de purulência do escarro. Esta definição pode ser qualificada também pela necessidade de introdução de tratamento com corticoide sistêmico e/ou antibiótico (Burgue et al., 2000). As exacerbações podem ser classificadas como leve, moderada ou grave. Nas exacerbações leves o paciente tem necessidade de aumentar a dose de medicação de manutenção, sem atendimento médico. Na moderada, é necessário aumento na medicação e atendimento médico. Pacientes que precisam ser hospitalizados são considerados portadores de exacerbação grave (Rodriguez-Roisin, 2000).

Vários marcadores têm sido associados à exacerbação e a morbi-mortalidade em pacientes com DPOC tais como a gravidade da obstrução ao fluxo aéreo, a intensidade da dispneia, a tolerância ao exercício, a anemia e o comprometimento das trocas gasosas, do estado nutricional e da qualidade de vida (Kessler et al., 1999; Nishimura et al., 2002; PintoPlata et al., 2004; Spencer et al., 2004; Schols et al., 2005; Chambellan et al., 2005). Por muitos anos, o $\mathrm{VEF}_{1}$ incorporado à idade foi considerado o preditor mais sensível de mortalidade em pacientes com DPOC (Anthonisen et al., 1986) e o menor valor do $\mathrm{VEF}_{1}$ pósbroncodilatador foi identificado como preditor de maior frequência de exacerbação da doença (Dewan et al., 2000). Além disso, pacientes que apresentaram exacerbação durante três anos de acompanhamento apresentaram valores basais de $\mathrm{VEF}_{1}$ menores quando comparados com aqueles que não exacerbaram durante o período (Spencer et al., 2004). As alterações das trocas gasosas são também preditoras da frequência de exacerbação, hospitalização e da sobrevida em pacientes com DPOC. A sobrevida foi menor em pacientes com valores menores de pressão arterial de oxigênio $\left(\mathrm{PaO}_{2}\right)$, pressão arterial de gás carbônico $\left(\mathrm{PaCO}_{2}\right)$ elevada e que desenvolveram cor pulmonale (Renzetti et al., 1966; Boushy et al., 1973; Postma et al., 1979).

A dispneia causada pelo exercício é um dos sintomas básicos em pacientes com DPOC, que aparece na fase inicial da doença e afeta as atividades de vida diária (Roca \& Rabinovich, 2003). Pacientes com escore de dispneia $\geq 3$, na escala Medical Research Council (MRC), apresentaram risco significativamente maior de hospitalização por exacerbação da doença quando comparados com aqueles com MRC igual a 2 (Kessler et al., 
1999). Além disso, a intensidade da dispneia apresentou maior associação com a sobrevida do que a classificação da gravidade da doença de acordo com os valores de $\mathrm{VEF}_{1}$, expressos como porcentagem dos valores previstos. (Nishimura et al., 2002). A sensação de dispneia foi também um dos indicadores da mortalidade no período de um ano, em 78 pacientes com DPOC muito grave em uso de oxigenoterapia independentemente dos valores do $\mathrm{VEF}_{1}$ (Coleta et al., 2008).

Além das alterações pulmonares causadas pela DPOC, as manifestações sistêmicas da doença também têm sido associadas com o prognóstico destes pacientes. A subnutrição afeta 26 a $47 \%$ dos pacientes com DPOC, começou a ser descrita como um sinal clínico na evolução da doença na década de 60 e está associada à menor sobrevida (Vandenbergh et al., 1967; Laaban et al., 1993; Paiva et al., 1996; Schols et al., 2000; Godoy et al., 2000). Vários estudos mostraram que o valor baixo do índice de massa do corpo (IMC) é um fator de risco independente para mortalidade (Wilson et al., 1989; Gray-Donald et al., 1996; Landbo et al., 1999). O valor do IMC e a perda de peso são também fatores de risco para exacerbação, hospitalização devido à exacerbação da doença, de pior prognóstico na evolução da agudização e podem predizer a necessidade de ventilação mecânica (Vitacca et al., 1996; Kessler et al., 1999, Hallin et al., 2006). As alterações da massa magra do corpo (MMC) também estão relacionadas com o prognóstico em pacientes com DPOC. Estudos mostram alta prevalência de diminuição da MMC que é preditora de mortalidade em pacientes com DPOC, independentemente dos valores de IMC (Schols et al., 2005; Vestbo et al., 2006).

A tolerância ao exercício, avaliada por meio da distância percorrida em seis minutos (DP6), pode ser um indicador de mortalidade melhor do que outros marcadores tradicionais de gravidade da doença (Celli et al., 2004; Pinto-Plata et al., 2004). Estudo controlado longitudinal que incluiu 198 pacientes com DPOC grave acompanhados durante dois anos mostrou que a DP6 não apresentou boa correlação com o $\mathrm{VEF}_{1}$ e foi o melhor indicador de sobrevida (Pinto-Plata et al., 2004). Em outro estudo, a evolução anual da DP6 foi avaliada em 294 pacientes com DPOC leve a muito grave durante o período de cinco anos. Os resultados mostraram que a taxa de declínio anual da DP6 foi maior nos pacientes com doença grave/muito grave e não apresentou correlação com a taxa de declínio do $\mathrm{VEF}_{1}$, a qual foi maior nos pacientes com doença moderada (Casanova et al., 2007).

A qualidade de vida relacionada à saúde é uma importante medida de desfecho em pacientes com DPOC, piora significativamente com a evolução da doença e foi identificada como preditora de mortalidade em pacientes com DPOC grave (Martinez et al., 2006; Oga et al., 2007). Valores basais dos escores do questionário de qualidade de vida SGRQ (Saint 
George's Respiratory Questionnaire) foram significativamente maiores nos pacientes que exacerbaram comparados com os pacientes que não exacerbaram durante período de três anos de acompanhamento (Spencer et al., 2004). Além disso, associação da qualidade de vida com a frequência de exacerbações, intensidade da dispneia e valores de $\mathrm{VEF}_{1}$ foi mostrada por Wang \& Bourbeau (2005).

A anemia é uma comorbidade comum em muitas doenças crônicas e estudos mostram que a prevalência em pacientes com DPOC varia entre 10 e 15\% (Chambellan et al., 2005; John et al., 2005). Chambellan et al., (2005) avaliaram associação entre hematócrito e o prognóstico em 2524 pacientes com DPOC recebendo oxigenoterapia domiciliar prolongada (ODP) e verificaram que o aumento de $5 \%$ no hematócrito foi associado com melhora da sobrevida. Em estudo retrospectivo recente, a anemia foi diagnosticada em 17\% dos 683 pacientes com DPOC e estava associada com dispneia mais intensa, diminuição da DP6 e pior sobrevida quando comparado com os pacientes não anêmicos (Cote et al., 2007).

Em resumo, vários índices foram estudados para prever a morbi-mortalidade na DPOC. No entanto, a maioria dos estudos utilizou marcadores isolados e o caráter sistêmico da doença indica a necessidade de investigações que avaliem a influência da combinação de vários parâmetros na ocorrência de exacerbações e na mortalidade de pacientes com DPOC. Com este objetivo foi desenvolvido o índice (BODE), englobando quatro aspectos fundamentais da doença: massa corpórea (Body mass index), obstrução das vias aéreas (Obstruction), dispneia (Dyspnea) e capacidade de exercício (Exercise) (Celli et al., 2004). O índice BODE foi preditor de morte devido complicações respiratórias mesmo após a correção para condições coexistentes e mostrou-se melhor preditor da mortalidade quando comparado ao $\mathrm{VEF}_{1}$ (Celli et al., 2004). A curva de sobrevida mostrou que valores do índice, de sete a dez, estavam associados à mortalidade de aproximadamente $80 \%$ em dois anos e quatro meses. Em estudo que avaliou 127 pacientes com DPOC, verificou-se que pacientes com escore alto no índice BODE apresentaram também maior frequência de hospitalização e mortalidade (Ong et al., 2005).

O impacto das exacerbações moderadas no índice BODE e em seus componentes foi avaliado em 205 pacientes com DPOC. O índice aumentou 1,38 pontos durante as exacerbações e permaneceu 0,8 e 1,1 pontos acima dos valores basais, após um e dois anos de acompanhamento, respectivamente (Cote et al., 2007). Marin et al., (2008) mostrou que o índice BODE foi melhor preditor do número e da gravidade das exacerbações em 275 pacientes com DPOC quando comparado com os valores de $\mathrm{VEF}_{1}$. Pacientes que apresentaram menores quartis do BODE apresentaram exacerbações moderadas, sem necessidade de 
hospitalização. No entanto, o aumento nos quartis do índice BODE foi associado com a ocorrência de exacerbações com necessidade de hospitalização, com um risco relativo de 2,9 (Marin et al., 2008).

Em estudo anterior realizado em nosso serviço (Faganello et al., 2010) foram avaliados os marcadores associados com a presença de exacerbação, no período de um ano. Cento e vinte pacientes com DPOC foram avaliados por meio de espirometria pré e pósbroncodilatador, medidas da composição do corpo, da intensidade da dispneia e da DP6 e o Índice BODE foi calculado levando em consideração os pontos de cortes propostos por Celli et al. (Celli et al., 2004). Sessenta pacientes (50\%) apresentaram pelo menos um episódio de exacerbação da doença e em 25 pacientes as exacerbações foram graves. O índice BODE e a classificação da gravidade da doença de acordo com as recomendações do GOLD tiveram influência similar no risco de exacerbações. $\mathrm{Na}$ análise de regressão logística múltipla para a classificação de gravidade de acordo com o GOLD e para as classes do BODE, a oximetria de pulso e a idade foram identificadas como preditoras da ocorrência de exacerbação.

Em resumo, o índice BODE é melhor preditor para mortalidade quando comparado aos valores do $\mathrm{VEF}_{1}$ e está relacionado com a frequência de hospitalizações (Celli et al., 2004; Ong et al., 2005). Adicionalmente, determina o impacto das exacerbações e é preditor do número e da gravidade das exacerbações em pacientes com DPOC (Cote et al., 2007; Marin et al., 2009). Além disso, estudos mostram que o índice BODE apresenta maior associação com o comprometimento da qualidade de vida em relação à gravidade da doença classificada pelo GOLD (Ong et al., 2006; Medina Amorós et al., 2009). Não identificamos estudos prévios que avaliaram a evolução dos marcadores diagnósticos e prognósticos em brasileiros com DPOC e a associação entre a evolução da qualidade de vida relacionada à saúde e das modificações do índice BODE em pacientes com DPOC leve a muito grave. 
Objetivos 


\section{OBJETIVOS}

Este estudo foi delineado para acompanhar pacientes com DPOC durante o período de três anos com os objetivos de avaliar:

Os preditores de exacerbação e mortalidade no período

A evolução dos marcadores diagnósticos e prognósticos nos sobreviventes

A associação entre a evolução da qualidade de vida relacionada à saúde e dos demais marcadores de diagnóstico e prognóstico da doença 
Pacientes e Métodos 


\section{PACIENTES E MÉTODOS}

\subsection{Pacientes}

Foram convidados a participar desta pesquisa os pacientes incluídos nos estudos "BODE Index and Gold Staging as Predictors of One-Year Exacerbation Risk in Chronic Obstructive Pulmonary Disease" (Faganello et al., 2010) e "Papel dos Mediadores Inflamatórios e da Vitamina A em Diferentes Estádios e nas Manifestações Clínicas da Doença Pulmonar Obstrutiva Crônica" (Ofício370/2004-CEP).

Os critérios de inclusão nos estudos prévios foram: pacientes com diagnóstico de DPOC feito por meio da história clínica, incluindo a exposição aos fatores de risco, evidências de hiperinsuflação ao exame físico e no estudo radiológico e confirmado pela presença de obstrução ao fluxo aéreo na espirometria pós-broncodilatador $\left(\mathrm{VEF}_{1} / \mathrm{CVF}<\right.$ 70\%) (Fabbri et al., 2006). Foram incluídos indivíduos que apresentaram estabilidade clínica, caracterizada pela ausência de exacerbação nos últimos três meses e em uso regular de medicação, incluindo a oxigenoterapia domiciliar prolongada (ODP). Os critérios de exclusão dos estudos foram: pacientes com asma, definida como aumento maior que $15 \%$ ou $200 \mathrm{ml}$ no $\mathrm{VEF}_{1}$ após administração de broncodilatador, incapacidade de realizar testes de função pulmonar e teste de caminhada de seis minutos, infarto do miocárdio dentro de quatro meses antes do início do estudo, angina instável ou insuficiência cardíaca congestiva (ICC) classe III e IV. O projeto atual foi aprovado pelo Comitê de Ética e Pesquisa da Faculdade de Medicina de Botucatu (Ofício 390/2007-CEP) (Anexo A).

\subsection{Delineamento}

Os cento e trinta e três pacientes com diagnóstico de DPOC foram avaliados nos estudos relatados acima e orientados a comparecer a cada seis meses nos Ambulatórios de Pneumologia da Faculdade de Medicina de Botucatu. Os pacientes ou seus familiares (em caso de óbito) foram contatados por telefone a cada três meses para verificar a evolução e foram feitas perguntas relacionadas ao uso de medicamentos, frequência das exacerbações, ocorrência e causa das hospitalizações e em caso de óbito, o motivo do mesmo (Apêndice A). 
Durante o período de acompanhamento, 15 pacientes (11\%) morreram, não foi possível contato com 9 (7\%) pacientes e 14 (10\%) foram excluídos por razões descritas na Figura 1. A avaliação dos preditores de frequência de exacerbação e/ou mortalidade foi feita em 124 pacientes e 95 realizaram avaliação antes e após três anos. Todos os pacientes foram informados sobre os objetivos, riscos e benefícios da pesquisa e somente foram incluídos após a assinatura do termo de consentimento livre e esclarecido (Apêndice B).

A avaliação após três anos foi similar à avaliação inicial. No primeiro dia, foram realizadas a avaliação clínica, a coleta de gases arteriais (nos pacientes com diagnóstico de DPOC grave e muito grave) e a espirometria (pré- e pós-broncodilatador). Em dia adicional, foi feita a avaliação da composição corporal, o teste de caminhada de seis minutos (DP6) e aplicados os questionários de qualidade de vida e de intensidade de dispneia.

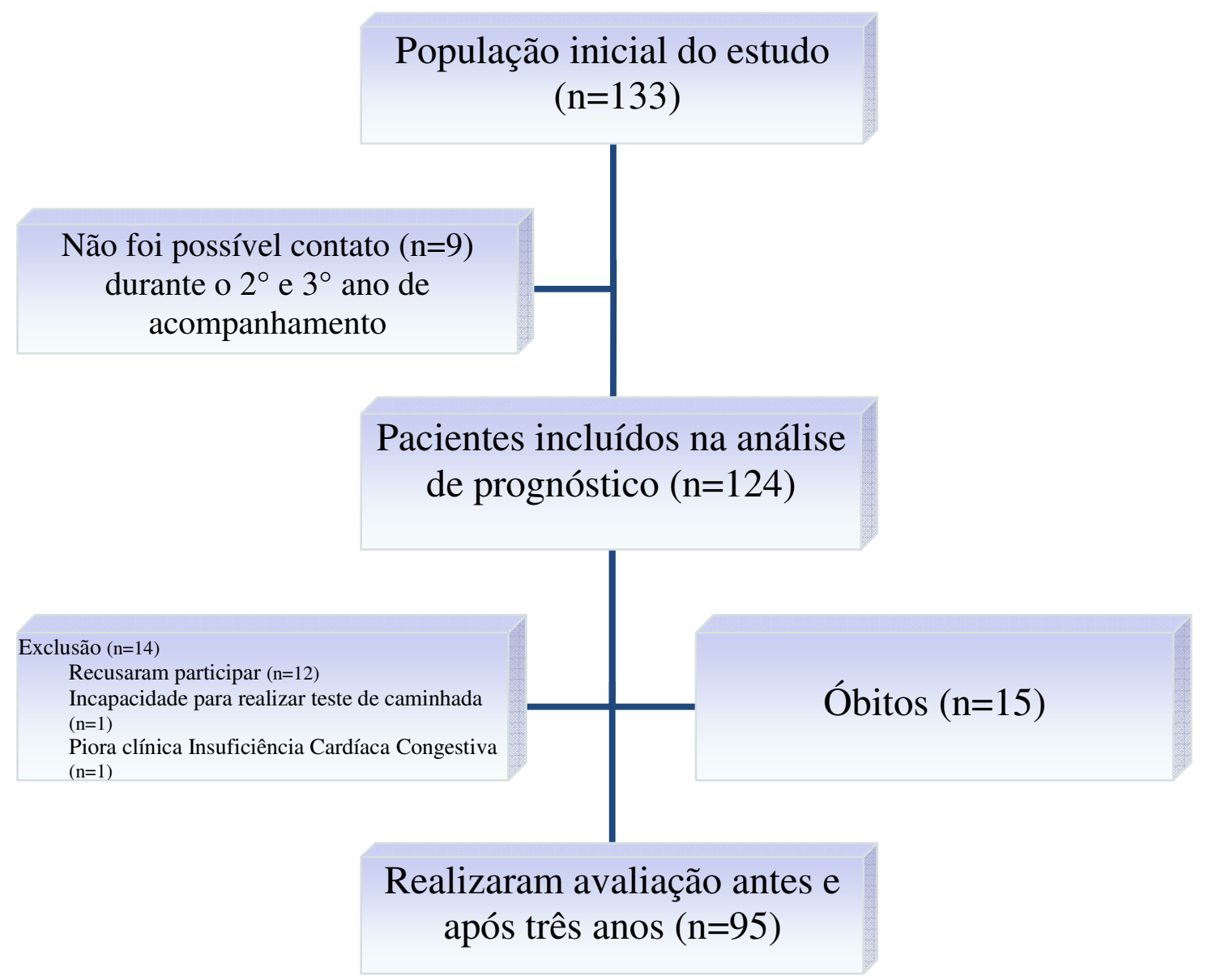

Figura 1. Diagrama de acompanhamento dos pacientes no período de três anos 


\subsection{Métodos}

\subsubsection{Espirometria e gases arteriais}

A espirometria foi realizada em sistema computadorizado de função pulmonar (Ferraris KOKO Louisville, CO 80027, USA) de acordo com os critérios da ATS (1987). Foram determinados o volume expiratório forçado no primeiro segundo $\left(\mathrm{VEF}_{1}\right)$, a capacidade vital forçada $(\mathrm{CVF})$ e a relação $\mathrm{VEF}_{1} / \mathrm{CVF}$, antes e após a administração de $400 \mathrm{mcg}$ de salbutamol por via inalatória. $\mathrm{O} \mathrm{VEF}_{1}$ foi expresso em litros (1), em porcentagem da CVF e como porcentagem dos valores de referência (Knudson et al., 1983). A monitorização da oximetria de pulso $\left(\mathrm{SpO}_{2}\right)$ foi realizada em todos os pacientes por meio de oxímetro portátil Onyx (Model 9500 Oximeter; Nonin Medical Inc.; Mineapolis, MN, USA). Nos pacientes com DPOC grau III e IV, os gases arteriais foram colhidos por punção da artéria radial, com o paciente em repouso e respirando ar ambiente. A dosagem foi realizada utilizando analisador de gases (Stat Profile 5 Plus - Nova Biomedical, Waltham, MA, USA).

\subsubsection{Avaliação nutricional}

A composição do corpo foi avaliada por meio da antropometria e impedância bioelétrica.

Antropometria: A estatura e o peso foram determinados em balança Filizola ${ }^{\circledR}$ com o paciente descalço e usando roupas leves e o índice de massa do corpo (IMC) foi calculado [IMC $=$ peso $(\mathrm{kg}) /$ estatura $\left.(\mathrm{m})^{2}\right]$.

Impedância bioelétrica: Antes das medidas, os pacientes foram orientados para esvaziar a bexiga, ficar em repouso durante trinta minutos e para retirar todos os objetos metálicos. A resistência foi medida do lado direito do corpo, por meio de quatro eletrodos de superfície colocados no punho e na região dorsal do pé, de acordo com protocolo de Kyle et al., (2004) (BIA 101, RJL Systems, Detroit, MI, USA). A massa magra do corpo (MMC) foi estimada por meio da equação desenvolvida para pacientes com insuficiência respiratória: MMC $=-6,06+($ estatura $\times 0,283)+($ peso $\times 10,207)-($ resistência $\times 1$ 0,024) $+[$ sexo $($ masculino $=1$, feminino $=0)$ x 4,036] (Kyle et al. 1998). $\mathrm{O}$ índice de massa magra do corpo foi calculado [IMMC $=\mathrm{MMC}(\mathrm{kg}) /$ estatura $(\mathrm{m})^{2}$ ] e a depleção nutricional foi definida por valores de IMMC $<15 \mathrm{~kg} / \mathrm{m}^{2}$, para mulheres e $<16 \mathrm{~kg} / \mathrm{m}^{2}$, para os homens (Schols et al., 2005). 


\subsubsection{Avaliação da Dispneia}

A versão traduzida para a língua brasileira do Baseline Dyspnea Index (BDI) (Martinez \& Padua, 2001), desenvolvido por (Mahler et al., 1984), foi um dos meios de avaliação da dispneia (Anexo B). Esta escala contém três componentes que avaliam aspectos importantes relacionados à dispneia. No primeiro, a intensidade da tarefa responsável por desencadear a dispneia é avaliada. No segundo, avalia-se a intensidade do esforço capaz de produzir dispneia. E no terceiro, leva-se em conta o grau de prejuízo funcional causado pela dispneia. Cada subitem varia de 0 a 4 . Um escore elevado representa melhor desempenho quanto ao sintoma. O escore total pode ser obtido somando-se os escores dos três domínios (0 a 12) ou a partir da média aritmética dos escores de cada subitem ( 0 a 4). Neste estudo, utilizou-se o primeiro método.

A dispneia foi também avaliada por meio do instrumento desenvolvido pelo Medical Research Council (MRC) e validado para a língua portuguesa por Kovelis et al., (2008). O MRC é baseado nas atividades que desencadeiam a dispneia, com escala de cinco pontos. Um número mais elevado indica maior sensação de dispneia.

Escala de Dispneia (MRC), (Kovelis et al., 2008)

\begin{tabular}{|c|l|}
\hline Grau 1 & Só sofre de falta de ar durante exercícios intensos. \\
\hline Grau 2 & $\begin{array}{l}\text { Sofre de falta de ar quando andando apressadamente ou } \\
\text { subindo uma rampa leve. }\end{array}$ \\
\hline Grau 3 & $\begin{array}{l}\text { Anda mais devagar do que pessoas da mesma idade por } \\
\text { causa de falta de ar ou tem que parar para respirar mesmo } \\
\text { quando andando devagar. }\end{array}$ \\
\hline Grau 4 & $\begin{array}{l}\text { Para para respirar depois de andar menos de 100 metros ou } \\
\text { após alguns minutos. }\end{array}$ \\
\hline Grau 5 & $\begin{array}{l}\text { Sente tanta falta de ar que não sai mais de casa, ou sente falta } \\
\text { de ar quando está se vestindo. }\end{array}$ \\
\hline
\end{tabular}




\subsubsection{Distância percorrida em seis minutos}

A distância percorrida em seis minutos (DP6) foi avaliada de acordo com os critérios da American Thoracic Society (Crapo et al., 2002). Delimitou-se um percurso a ser seguido, corredor de 30 metros, e os pacientes foram instruídos a caminhar o máximo que conseguissem por um período de tempo designado de seis minutos. Os pacientes podiam parar durante o teste, mas foram instruídos para retomar a caminhada assim que fossem capazes. Depois de decorridos os seis minutos, foram instruídos a parar de andar e mensurou-se a distância total da caminhada, em metros. Durante o teste foram verificados a oximetria de pulso $\left(\mathrm{SpO}_{2}\right)$ e a frequência de pulso dos pacientes por meio do oxímetro portátil (Marca Moriya, modelo 1001, São Paulo, Brasil) o qual foi transportado pelo paciente em uma mochila. Antes e após o teste, foram verificadas também a pressão arterial, a frequência cardíaca, a frequência respiratória e a presença de dispneia e de fadiga nos membros inferiores por meio da escala de Borg (Borg, 2000) (Anexo C). Os pacientes com hipoxemia crônica ou que apresentaram $\mathrm{SpO}_{2}<85 \%$ durante o teste foram suplementados com oxigênio. Neste caso, o fisioterapeuta caminhou ao lado do paciente levando o cilindro em carrinho portátil e a suplementação foi repetida nas reavaliações da medida.

\subsubsection{Qualidade de vida relacionada à saúde}

O instrumento utilizado foi a versão validada para a língua e cultura brasileiras do Questionário do Hospital Saint George na Doença Respiratória (SGRQ) (Sousa et al., 2000). O SGRQ inclui os domínios: sintomas, relativo ao desconforto causado por sintomas respiratórios; impacto, avaliando o impacto global nas atividades de vida e no bem estar do paciente; atividades, que considera as alterações da atividade física e o escore total, que corresponde à somatória dos três domínios (Anexo D). O escore de cada domínio e o escore total têm pontuação de zero (ausência de disfunção) a 100 (disfunção máxima). Os resultados são expressos em porcentagem, sendo que modificações acima de $4 \%$ refletem diferença clinicamente significativa para cada domínio (Schunemann et al., 2003). 


\subsection{6. Índice BODE}

As variáveis e os pontos de cortes foram os mesmos utilizados no estudo de Celli et al., (2004) e estão representados na tabela abaixo:

\begin{tabular}{lcccc}
\hline Variáveis & \multicolumn{5}{c}{ Pontos de corte (Índice BODE) } \\
\hline & $\mathbf{0}$ & $\mathbf{1}$ & $\mathbf{2}$ & $\mathbf{3}$ \\
$\mathrm{VEF}_{1}$ (\% do previsto) & $\geq 65$ & $50-64$ & $36-49$ & $\leq 35$ \\
Distância percorrida em 6 minutos (m) & $\geq 350$ & $250-349$ & $150-249$ & $\leq 149$ \\
Escala de dispneia (MRC) & $0-1$ & 2 & 3 & 4 \\
Índice Massa do corpo $\left(\mathrm{Kg} / \mathrm{m}^{2}\right)$ & $>21$ & $\leq 21$ & & \\
\hline
\end{tabular}

O índice BODE foi separado em 4 classes: 1 (escore 0 a 2); 2 (escore 3 e 4); 3 (escore (5 e 6) e 4 (escore 7 a 10).

\subsubsection{Comorbidades}

A presença de comorbidades associadas à DPOC foi avaliada por meio do índice de Charlson (Charlson et al., 1994). Este índice foi desenvolvido para calcular o risco de morte dos pacientes com doença crônica, combinando a idade com as doenças associadas. Cada doença tem pontuação específica e proporcional à gravidade. Pontuação 1 é atribuída a infarto do miocárdio, insuficiência cardíaca congestiva, doença vascular periférica, doença cerebrovascular, demência, doença pulmonar crônica, doença do tecido conjuntivo, doença ulcerosa gástrica, hepatopatia leve e diabetes. Pontuação 2 é atribuída a diabetes com lesão de órgão alvo, hemiplegia, doença renal e doenças malignas. Pontuação 3 é atribuída para hepatopatia moderada a grave, enquanto que AIDS e tumor sólido metastático recebem pontuação 6. Para cada década de vida acima dos 40 anos, adiciona-se um ponto ao risco (Anexo E). 


\subsubsection{Hemograma}

Exames hematológicos foram realizados de acordo com os critérios empregados na realização dos exames de rotina da Seção Técnica de Laboratório e Análises Clínicas do HC/UNESP/Botucatu. Os valores de normalidade para hematócrito foram: 37 a 47\% para mulheres e 40 a 57\% para homens, de acordo com a Organização Mundial de Saúde (WHO, 1968)

\subsubsection{Exacerbações}

Foram consideradas as exacerbações moderadas (necessidade de alteração na medicação de manutenção ou necessidade de introduzir o uso de corticoide e/ou antibiótico) e as exacerbações graves (necessidade de hospitalização). O questionário aplicado aos pacientes para verificar a frequência de exacerbações está mostrado no apêndice A.

\subsubsection{Análise estatística}

A análise dos dados foi realizada usando os pacotes estatísticos SigmaStat 3.2 (Inc, Chicago, IL, USA) e STATA 10.0 (Stata Corp, Texas, USA). Para identificar os preditores de mortalidade nos 124 pacientes estudados, foi utilizada a análise de regressão de Cox. A análise de regressão de Poisson foi realizada para avaliar a associação entre os marcadores da doença e a frequência de exacerbação. Para os dois modelos de regressão, foram selecionadas variáveis com relevância clínica e que não apresentassem colinearidade entre si. As variáveis categóricas incluídas foram: gênero (feminino=0 e masculino=1), índice BODE quartis (classe $1=$ escore 0 a 2, classe $2=$ escore 3 e 4 , classe $3=$ escore 5 e 6 e classe $4=$ escore 7 a 10 ) e para o hematócrito, foram criadas variáveis dummys ( 0 e 1), com hematócrito baixo ( $<40 \%$ para homens e $<37 \%$ para mulheres) e hematócrito alto ( $>57 \%$ para homens e $>47 \%$ para mulheres). As variáveis contínuas foram: idade, $\mathrm{SpO}_{2}$, índice Charlson e o número total de exacerbação. As variáveis contínuas $\mathrm{VEF}_{1}$, DP6, MRC e IMC foram usadas num segundo modelo para substituir o índice BODE. A gravidade da doença, classificada pelo GOLD, foi colocada num terceiro modelo substituindo o $\mathrm{VEF}_{1}$. 
A avaliação da evolução dos marcadores nos pacientes reavaliados após três anos foi realizada por meio do teste " $T$ " para medidas repetidas para variáveis contínuas e o teste de Wilcoxon para variáveis não paramétricas. Para a comparação de dois grupos (pacientes excluídos e avaliados após três anos) foi utilizado o teste " $T$ " para variáveis com distribuição normal e Mann-Whitney para variáveis com distribuição não normal. Para avaliação de duas variáveis qualitativas binárias com frequência maior que cinco foi utilizado o teste de Quiquadrado. Análise de regressão logística múltipla foi feita para avaliar os preditores de piora ou melhora clinicamente significativa da qualidade de vida relacionada à saúde. O nível de significância adotado foi de $5 \%$ para todos os testes. 
Resultados 


\section{RESULTADOS}

\section{Análise dos preditores de mortalidade $(n=124)$}

Os preditores de mortalidade foram analisados incluindo a amostra de 124 pacientes em que esta variável foi analisada. Durante o período de estudo 15 pacientes morreram e as causas dos óbitos foram: complicações pulmonares decorrentes da DPOC em oito pacientes, doenças cardiovasculares em cinco, abscesso esplênico e choque séptico em um paciente e neoplasia maligna do cólon em um paciente. Destes pacientes, três apresentavam DPOC leve, dois DPOC moderada, um DPOC grave e nove apresentavam DPOC muito grave.

Os resultados da análise de regressão de Cox mostraram que o aumento da idade e nos quartis do índice BODE foram os marcadores associados com a mortalidade (Tabela 1).

Tabela 1. Análise de regressão de Cox para identificar os preditores de mortalidade no período de três anos $(\mathrm{n}=124)$

\begin{tabular}{lcc}
\hline \hline \multicolumn{1}{c}{ Variáveis } & Risco Relativo (95\% IC) & Valor de p \\
\hline Sexo masculino & $1,538(0,225-10,517)$ & 0,661 \\
Idade (anos) & $1,208(1,026-1,421)$ & $\mathbf{0 , 0 2 3}$ \\
$\mathrm{SpO}_{2}(\%)$ & $1,041(0,839-1,291)$ & 0,711 \\
Índice BODE quartis & $3,014(1,330-6,829)$ & $\mathbf{0 , 0 0 8}$ \\
Índice Charlson & $0,439(0,166-1,162)$ & 0,098 \\
Hematócrito $(\%)$ baixo & $3,400(0,346-33,384)$ & 0,294 \\
Hematócrito $(\%)$ alto & $0,619(0,701-5,466)$ & 0,666 \\
Exacerbação & $0,676(0,438-1,045)$ & 0,078 \\
\hline \hline
\end{tabular}

$\mathrm{SpO}_{2}$ : oximetria de pulso; Índice BODE quartis: classe 1(escore 0 a 2), classe 2 (escore 3 e 4), classe 3 (escore 5 e 6) e classe 4 (escore 7 a 10); hematócrito baixo ( $<40 \%$ para homens e $<37 \%$ para mulheres) e hematócrito alto (>57\% para homens e >47\% para mulheres); exacerbação: número de exacerbações por paciente no período de três anos; $\mathrm{p}<0,05$. 
Ao substituir o índice BODE pelas variáveis que o constitui (IMC, $\mathrm{VEF}_{1}, \mathrm{MRC}$ e DP6), apenas o aumento na idade foi preditor de mortalidade no modelo de regressão de Cox (Tabela 2).

Tabela 2. Análise de regressão de Cox para identificar os preditores de mortalidade no período de três anos $(\mathrm{n}=124)$

\begin{tabular}{|c|c|c|}
\hline Variáveis & Risco Relativo (95\% IC) & Valor de $p$ \\
\hline Sexo masculino & $0,691(0,100-4,773)$ & 0,708 \\
\hline Idade (anos) & $1,183(1,005-1,394)$ & 0,044 \\
\hline $\mathrm{SpO}_{2}(\%)$ & $0,859(0,669-1,104)$ & 0,237 \\
\hline DP6 (m) & $1,002(0,993-1,012)$ & 0,600 \\
\hline $\operatorname{VEF}_{1}(\%)$ & $1,004(0,9784-1,036)$ & 0,764 \\
\hline $\operatorname{IMC}\left(\mathrm{kg} / \mathrm{m}^{2}\right)$ & $0,874(0,740-1,033)$ & 0,116 \\
\hline MRC (escore) & $1,197(0,548-2,613)$ & 0,652 \\
\hline Índice Charlson & $0,535(0,228-1,259)$ & 0,153 \\
\hline Hematócrito (\%) baixo & $3,079(0,242-39,129)$ & 0,386 \\
\hline Hematócrito (\%) alto & $0,389(0,352-4,293)$ & 0,441 \\
\hline Exacerbação & $0,079(0,542-1,167)$ & 0,242 \\
\hline
\end{tabular}


Ao substituir o $\mathrm{VEF}_{1}$ pela gravidade da doença, classificada pelo GOLD, não identificamos preditores de mortalidade (Tabela 3).

Tabela 3. Análise de regressão de Cox para identificar os preditores de mortalidade no período de três anos $(n=124)$

\begin{tabular}{lcc}
\hline \multicolumn{1}{c}{ Variáveis } & Risco Relativo (95\% IC) & Valor de p \\
\hline Sexo masculino & $0,845(0,127-5,593)$ & 0,861 \\
Idade (anos) & $1,123(0,880-1,277)$ & 0,075 \\
$\mathrm{SpO}_{2}(\%)$ & $0,902(0,700-1,163)$ & 0,428 \\
DP6 (m) & $1,005(0,995-1,015)$ & 0,258 \\
GOLD classes & $1,954(0,884-4,317)$ & 0,098 \\
IMC (kg/m $\left.{ }^{2}\right)$ & $0,870(0,737-1,028)$ & 0,103 \\
MRC (escore) & $1,180(0,555-2,508)$ & 0,666 \\
Índice Charlson & $0,633(0,267-1,499)$ & 0,299 \\
Hematócrito (\%) baixo & $7,759(0,624-38,124)$ & 0,111 \\
Hematócrito (\%) alto & $0,385(0,345-4,299)$ & 0,438 \\
Exacerbação & $0,648(0,410-1,025)$ & 0,064 \\
\hline
\end{tabular}

$\mathrm{SpO}_{2}$ : oximetria de pulso; DP6: distância percorrida em 6 minutos; GOLD classes: classe I (DPOC leve), II (DPOC moderada), III (DPOC grave), IV (DPOC muito grave); IMC: índice massa do corpo; MRC: Medical Research Council; hematócrito baixo ( $<40 \%$ para homens e $<37 \%$ para mulheres) e hematócrito alto ( $>57 \%$ para homens e $>47 \%$ para mulheres); exacerbação: número de exacerbações por paciente no período de três anos; $\mathrm{p}<0,05$. 
Análise dos preditores de exacerbação $(\mathbf{n}=124)$

Os preditores de exacerbação foram analisados incluindo a amostra de 124 pacientes em que esta variável foi analisada. Noventa e três pacientes $(75 \%)$ apresentaram pelo menos uma exacerbação no período do estudo e em 33 pacientes (26,6\%) as exacerbações foram graves. A distribuição dos pacientes que apresentaram pelo menos uma exacerbação de acordo com a gravidade da doença está representada na Figura 2.

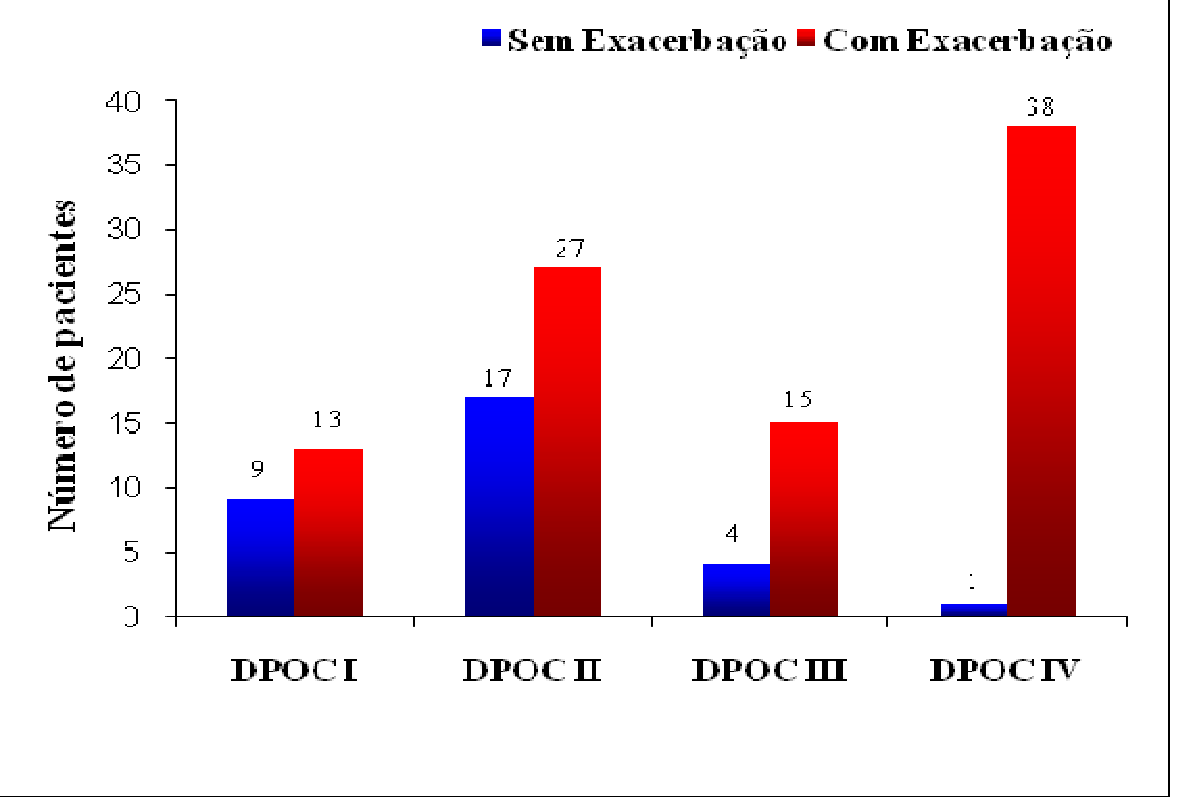

Figura 2. Pacientes que apresentaram pelo menos uma exacerbação de acordo com a gravidade da DPOC no período de três anos 
Os resultados da análise de regressão de Poisson mostram que os quartis do índice BODE e a $\mathrm{SpO}_{2}$, avaliados no momento basal, foram as variáveis associadas com a frequência de exacerbação (Tabela 4).

Tabela 4. Análise de regressão de Poisson para identificar os preditores para frequência de exacerbação no período de três anos $(n=124)$

\begin{tabular}{lcc}
\hline \hline \multicolumn{1}{c}{ Variáveis } & Coeficiente $(\mathbf{9 5 \%}$ IC) & Valor de p \\
\hline Sexo masculino & $0,890(0,643-1,231)$ & 0,484 \\
Idade (anos) & $1,019(0,994-1,044)$ & 0,133 \\
$\mathrm{SpO}_{2}(\%)$ & $0,939(0,897-0,983)$ & $\mathbf{0 , 0 0 7}$ \\
Índice BODE quartis & $1,389(1,180-1,637)$ & $<\mathbf{0 , 0 0 1}$ \\
Índice Charlson & $0,977(0,855-1,116)$ & 0,737 \\
Hematócrito (\%) baixo & $1,521(0,857-2,699)$ & 0,152 \\
Hematócrito (\%) alto & $1,053(0,723-1,534)$ & 0,787 \\
\hline \hline
\end{tabular}

$\mathrm{SpO}_{2}$ : oximetria de pulso; Índice BODE quartis: classe 1(escore 0 a 2), classe 2 (escore 3 e 4), classe 3 (escore 5 e 6) e classe 4 (escore 7 a 10); hematócrito baixo ( $<40 \%$ para homens e $<37 \%$ para mulheres) e hematócrito alto ( $>57 \%$ para homens e $>47 \%$ para mulheres); $p<0,05$. 
Quando o índice BODE foi substituído pelas variáveis que o constitui (IMC, $\mathrm{VEF}_{1}, \mathrm{MRC}$ e DP6) no modelo de regressão de Poisson, as variáveis associadas com a frequência de exacerbação foram: $\mathrm{SpO}_{2}, \mathrm{VEF}_{1}$, IMC e o hematócrito baixo (Tabela 5).

Tabela 5. Análise de regressão de Poisson para identificar os preditores para frequência de exacerbação no período de três anos $(n=124)$

\begin{tabular}{|c|c|c|}
\hline Variáveis & Coeficiente (95\% IC) & Valor de $p$ \\
\hline Sexo masculino & $0,780(0,562-1,083)$ & 0,139 \\
\hline Idade (anos) & $1,016(0,991-1,041)$ & 0,190 \\
\hline $\mathrm{SpO}_{2}(\%)$ & $0,932(0,886-0,979)$ & 0,006 \\
\hline DP6 (m) & $1,001(0,999-1,003)$ & 0,268 \\
\hline $\mathrm{VEF}_{1}(\%)$ & $0,986(0,978-0,994)$ & 0,001 \\
\hline $\operatorname{IMC}\left(\mathrm{kg} / \mathrm{m}^{2}\right)$ & $0,969(0,942-0,998)$ & 0,036 \\
\hline MRC (escore) & $1,019(0,873-1,189)$ & 0,808 \\
\hline Índice Charlson & $0,993(0,868-1,136)$ & 0,928 \\
\hline Hematócrito (\%) baixo & $1,967(1,087-3,559)$ & 0,025 \\
\hline Hematócrito (\%) alto & $1,051(0,713-1,549)$ & 0,800 \\
\hline
\end{tabular}

$\mathrm{SpO}_{2}$ : oximetria de pulso; DP6: distância percorrida em 6 minutos; $\mathrm{VEF}_{1}$ : volume expiratório forçado no primeiro segundo; IMC: índice de massa do corpo; MRC: Medical Research Council; hematócrito baixo ( $<40 \%$ para homens e $<37 \%$ para mulheres) e hematócrito alto ( $>57 \%$ para homens e $>47 \%$ para mulheres); $\mathrm{p}<0,05$. 
Quando a gravidade da doença, classificada pelo GOLD foi colocada no modelo de regressão de Poisson, o aumento nas classes de gravidade da doença foi preditor para frequência de exacerbação (Tabela 6).

Tabela 6. Análise de regressão de Poisson para identificar os preditores para frequência de exacerbação no período de três anos $(n=124)$

\begin{tabular}{lcc}
\hline \hline \multicolumn{1}{c}{ Variáveis } & Coeficiente $(\mathbf{9 5 \%}$ IC) & Valor de p \\
\hline Sexo masculino & $0,795(0,558-1,132)$ & 0,205 \\
Idade (anos) & $1,016(0,990-1,043)$ & 0,215 \\
$\mathrm{SpO}_{2}(\%)$ & $0,974(0,921-1,030)$ & 0,362 \\
$\mathrm{DP6}(\mathrm{m})$ & $1,001(0,999-1,003)$ & 0,217 \\
$\mathrm{GOLD}$ classes & $1,527(1,270-1,837)$ & $<\mathbf{0 , 0 0 1}$ \\
IMC (kg/m $\left.{ }^{2}\right)$ & $0,973(0,944-1,002)$ & 0,070 \\
MRC (escore) & $1,035(0,883-1,213)$ & 0,668 \\
Índice Charlson & $0,977(0,847-1,127)$ & 0,752 \\
Hematócrito (\%) baixo & $1,810(0,949-3,450)$ & 0,071 \\
Hematócrito (\%) alto & $1,062(0,698-1,616)$ & 0,778 \\
\hline
\end{tabular}

$\mathrm{SpO}_{2}$ : oximetria de pulso; DP6: distância percorrida em 6 minutos; GOLD classes: classe I (DPOC leve), II (DPOC moderada), III (DPOC grave), IV (DPOC muito grave); IMC: índice massa do corpo; MRC: Medical Research Council; hematócrito baixo ( $<40 \%$ para homens e $<37 \%$ para mulheres) e hematócrito alto ( $>57 \%$ para homens e $>47 \%$ para mulheres); $\mathrm{p}<0,05$. 


\section{Análise da evolução dos marcadores diagnósticos no período de três anos $(\mathbf{n = 9 5 )}$}

Dos 133 pacientes inicialmente considerados para o estudo evolutivo, 95 foram submetidos à segunda avaliação após três anos. A idade média inicial dos 95 pacientes (66\% homens) foi de $64 \pm 9$ anos. A comparação entre as características dos pacientes excluídos e dos pacientes reavaliados após três anos não identificou diferença estatística (Tabela 7).

Tabela 7. Comparação das características dos pacientes excluídos e dos pacientes avaliados após três anos

\section{Variáveis \\ Pacientes excluídos Pacientes estudados \\ Valor p}

\begin{tabular}{|c|c|c|c|}
\hline & $(n=23)$ & $(n=95)$ & \\
\hline Gênero F/M (n) & $7 / 16$ & $32 / 63$ & 0,960 \\
\hline Idade (anos) & $64 \pm 11$ & $64 \pm 9$ & 0,850 \\
\hline $\mathrm{VEF}_{1}(\%)$ & $71(46-78)$ & $54(41-73)$ & 0,221 \\
\hline CVF (\%) & $104(78-114)$ & 86 (74-104) & 0,179 \\
\hline $\mathrm{VEF}_{1} / \mathrm{CVF}$ & $54(47-64)$ & $53(43-63)$ & 0,412 \\
\hline $\mathrm{IMC}\left(\mathrm{kg} / \mathrm{m}^{2}\right)$ & $25(21-29)$ & $25(22-29)$ & 0,788 \\
\hline DP6 (m) & $427 \pm 104$ & $438 \pm 85$ & 0,615 \\
\hline MRC (escore) & $1(1-2)$ & $1(1-2)$ & 0,581 \\
\hline $\mathrm{SpO}_{2}(\%)$ & $94(93-96)$ & $94(92-86)$ & 0,456 \\
\hline Índice BODE & $2(0-3)$ & $2(1-4)$ & 0,206 \\
\hline Índice Charlson & $4(2-4)$ & $3(3-4)$ & 0,816 \\
\hline
\end{tabular}

Valores estão apresentados como média \pm desvio padrão ou mediana (quartis 25-75). VEF$_{1}$ : volume expiratório forçado no primeiro segundo; CVF: capacidade vital forçada; IMC: índice massa do corpo; DP6: distância percorrida em 6 minutos; MRC: Medical Research Council; $\mathrm{SpO}_{2}$ : oximetria de pulso. Teste "T" ou Mann-Whitney; $p<0,05$. 
Entre os pacientes reavaliados, 17 apresentaram DPOC leve, 37 moderada, 18 grave e 23 DPOC muito grave no momento basal. Não houve diferença na proporção de pacientes entre as diferentes gravidades da doença após três anos $(\mathrm{p}=0,865)$, como mostrado na Figura 3.

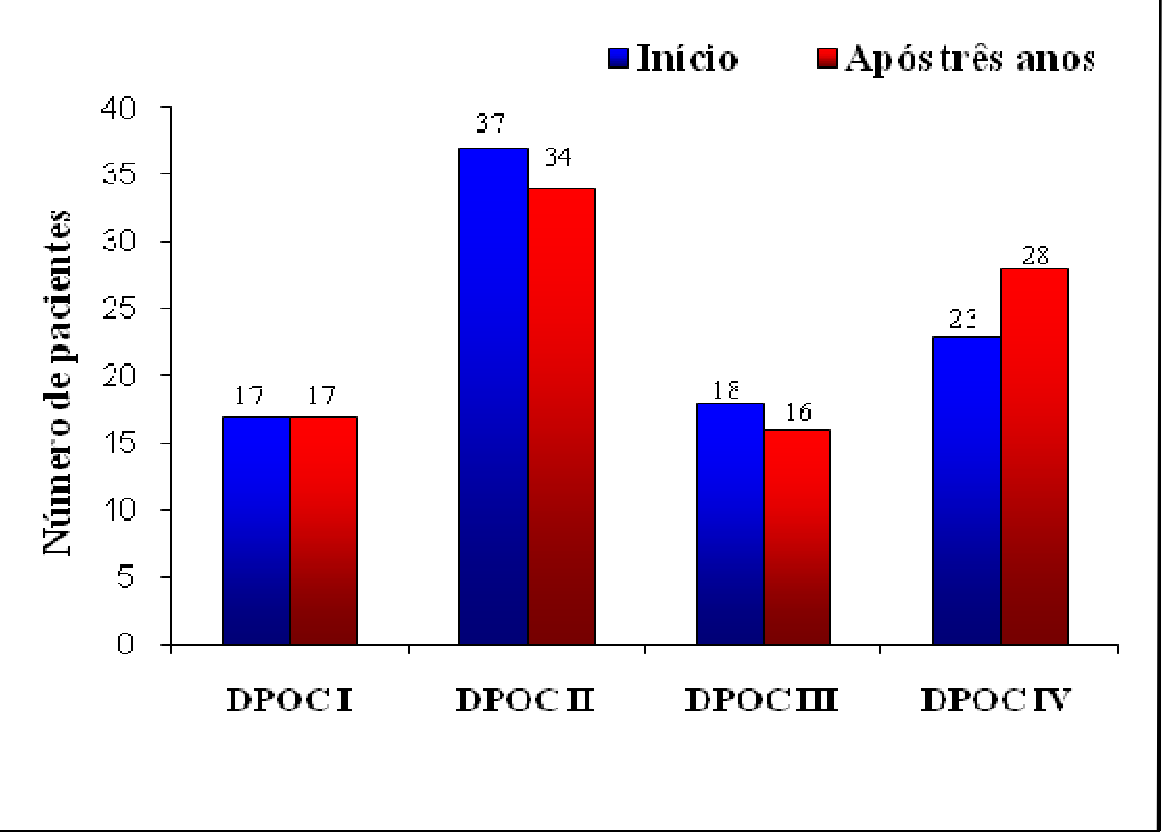

Figura 3. Proporção de pacientes de acordo com a gravidade da DPOC no início e após três $\operatorname{anos}(\mathrm{p}=0,865)$ 
Entre os pacientes reavaliados, 57 pertenciam à classe I do índice BODE, 21 classe II e 17 pertenciam à classe III no momento basal. Houve diferença na proporção de pacientes entre as classes do BODE após três anos ( $\mathrm{p}=0,05)$, como mostrado na Figura 4.

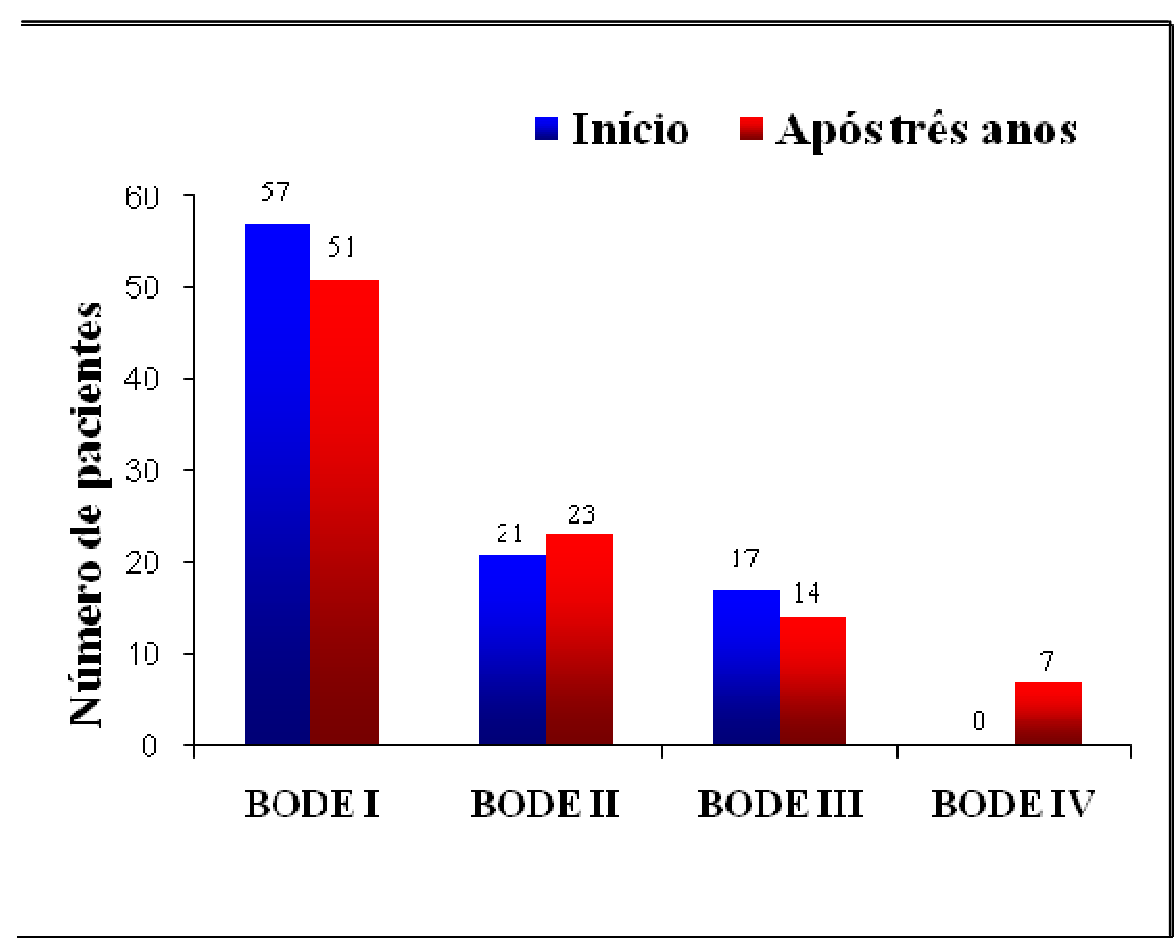

Figura 4. Proporção de pacientes de acordo com as classes do BODE no início e após três $\operatorname{anos}(\mathrm{p}=0,05)$ 
No Quadro 1 estão relacionadas as medicações de manutenção utilizadas pelos 95 pacientes no momento basal, de acordo com a gravidade da doença.

Quadro 1. Classe de medicamentos em uso contínuo pelos pacientes estudados

\begin{tabular}{lcccc}
\hline \hline Medicamento & I & II & III & IV \\
& $\mathbf{n = 1 7}$ & $\mathbf{n = 3 7}$ & $\mathbf{n = 1 8}$ & $\mathbf{n = 2 3}$ \\
\hline Corticosteroide inalado & 0 & 2 & 1 & 2 \\
$\beta 2$ agonista de longa duração inalado & 1 & 8 & 7 & 8 \\
$\beta 2$ agonista de curta duração inalado & 0 & 6 & 3 & 6 \\
Brometo de ipatrópio & 0 & 6 & 2 & 4 \\
Brometo de tiotrópio & 0 & 0 & 0 & 1 \\
$\beta 2$ longa + corticosteroide inalado & 4 & 8 & 5 & 8 \\
$\beta 2$ longa + tiotrópio + corticosteroide & 0 & 0 & 0 & 0 \\
Oxigenoterapia Domiciliar Prolongada & 0 & 0 & 0 & 19 \\
Nenhuma medicação & 12 & 11 & 2 & 2 \\
\hline \hline
\end{tabular}

A evolução das características dos pacientes após três anos está mostrada na Tabela 8. Não houve alteração significativa nos valores do $\mathrm{VEF}_{1}$ e da $\mathrm{CVF}$, após broncodilatador, expressos em \% dos valores previstos e dos atributos de composição do corpo no período. $\mathrm{O}$ valor do $\mathrm{VEF}_{1}$, em litros, piorou significativamente, com diminuição de $0,061(0,04-0,1851)$ e com variação de $5,36 \%(2,79-14,6 \%)$, apresentados como mediana ( $1^{\circ}$ e $3^{\circ}$ quartil). $\mathrm{O}$ valor da CVF, em litros, também piorou significativamente durante o período. Houve piora significativa da $\mathrm{SpO}_{2}$ e do Índice BODE quando comparados ao momento basal.

Em relação ao índice BODE, de acordo com o sugerido por Martinez et al., (2008), 41 pacientes (43\%) apresentaram estabilidade do índice, 37 (39\%) apresentaram piora $\geq 1$ ponto e $17(18 \%)$ pacientes tiveram melhora $\geq 1$ ponto. Entre as variáveis que compõem o índice BODE, 35 pacientes aumentaram o índice por aumento no MRC, 6 por diminuição da DP6 e 7 apresentaram as alterações concomitantes. 
Tabela 8. Evolução das características de pacientes com DPOC após três anos

\begin{tabular}{|c|c|c|c|}
\hline Variáveis & $\begin{array}{l}\text { Avaliação inicial } \\
\qquad(\mathrm{n}=95)\end{array}$ & $\begin{array}{l}\text { Avaliação final } \\
\qquad(n=95)\end{array}$ & $\overline{\text { Valor } \mathbf{p}}$ \\
\hline $\mathrm{VEF}_{1}(\%)$ & $54(41-73)$ & $54(40-70)$ & 0,228 \\
\hline $\mathrm{VEF}_{1}(1)$ & $1,25(0,95-1,72)$ & $1,25(0,87-1,60)$ & $<0,001$ \\
\hline $\operatorname{CVF}(\%)$ & $86(74-104)$ & $87(71-106)$ & 0,167 \\
\hline CVF (1) & $2,7(2,2-3,0)$ & $2,4(1,9-3,0)$ & $\mathbf{0 , 0 0 2}$ \\
\hline $\mathrm{VEF}_{1} / \mathrm{CVF}$ & $52 \pm 12$ & $51 \pm 10$ & 0,123 \\
\hline $\mathrm{IMC}\left(\mathrm{kg} / \mathrm{m}^{2}\right)$ & $25(22-29)$ & $25(22-29)$ & 0,382 \\
\hline MMC (kg) & $42(38-47)$ & $41(37-47)$ & 0,805 \\
\hline Deplet/ não deplet (n) & $38 / 57$ & $41 / 54$ & 0,768 \\
\hline $\mathrm{SpO}_{2}(\%)$ & $94(92-96)$ & $93(90-95)$ & $<0,001$ \\
\hline Índice BODE & $2,2 \pm 1,8$ & $2,6 \pm 2,3$ & 0,008 \\
\hline
\end{tabular}

Valores estão apresentados como média \pm desvio padrão ou mediana (quartis $25-75$ ). $V E F_{1}$ : volume expiratório forçado no primeiro segundo; CVF: capacidade vital forçada; IMC: índice massa do corpo; MMC: massa magra do corpo; Deplet/ não deplet: número de pacientes com depleção de massa magra/sem depleção massa magra; $\mathrm{SpO}_{2}$ : oximetria de pulso. Teste " $\mathrm{T}$ " para medidas repetidas ou Wilcoxon; $\mathrm{p}<0,05$.

O índice Charlson aumentou significativamente no período [3 (3-4) vs 4 (3-5); p=0,009]. Em 20 pacientes, o aumento ocorreu devido à mudança na década de vida. 
A DP6 diminuiu significativamente após três anos $(438 \pm 86 \mathrm{~m}$ vs $412 \pm 100 \mathrm{~m}$; $p=0,001)$, como mostrado na Figura 5. Piora clinicamente significativa ( $\geq 54 \mathrm{~m}$ ) ocorreu em 31 pacientes (32\%), sendo que 18 destes pacientes (58\%) apresentavam doença grave ou muito grave.

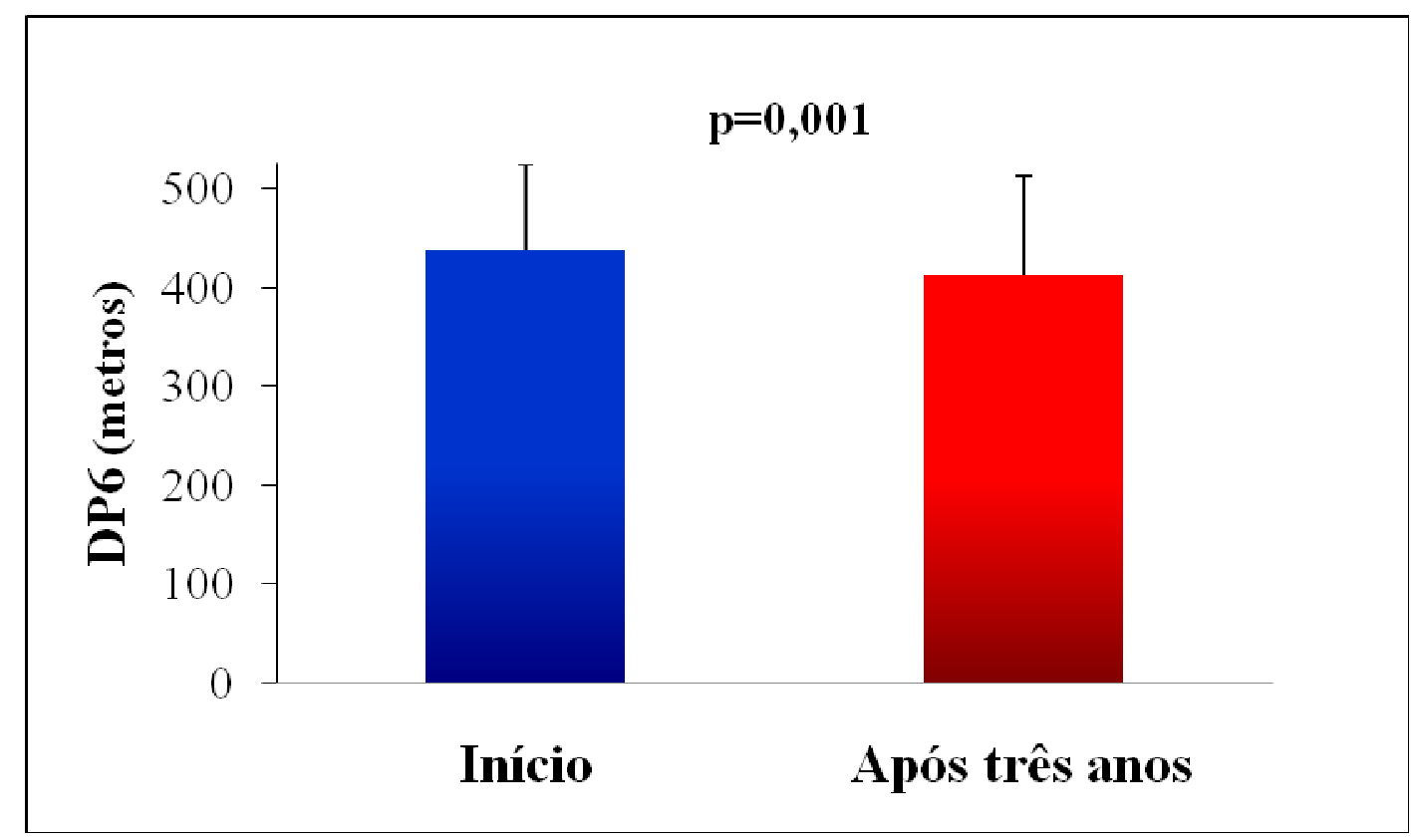

Figura 5. Evolução da DP6 em pacientes com DPOC no período de três anos 
A percepção da intensidade de dispneia, avaliada pelo MRC [1 (1-2) vs 2 (1-3); $\mathrm{p}=0,002]$ e BDI [6,5 (4-9) vs 5 (3-8); $\mathrm{p}<0,001]$, aumentou significativamente no período do estudo (Figura 6).

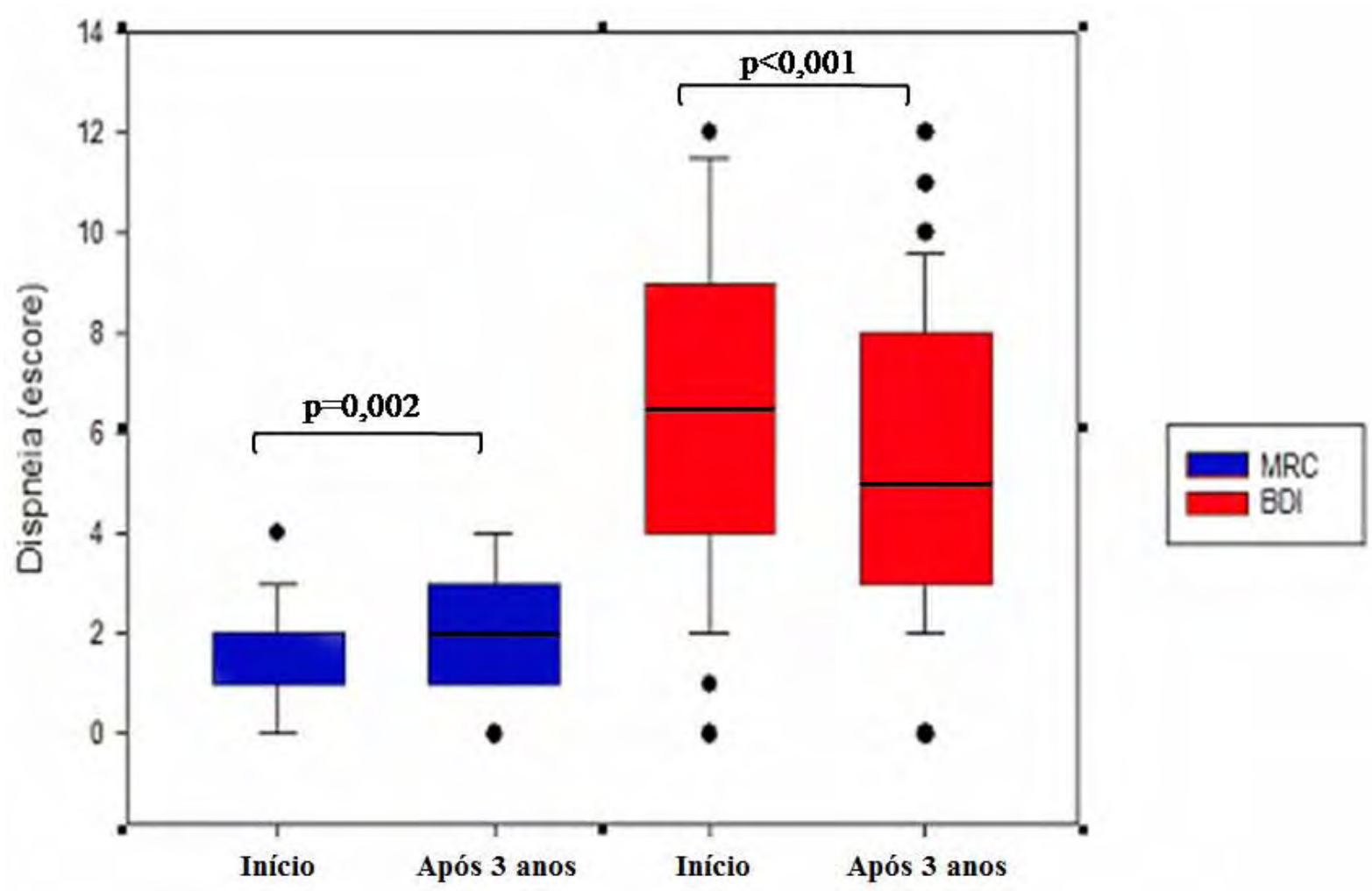

Figura 6. Evolução da dispneia avaliada pelo MRC e BDI após três anos 
O estado geral de saúde avaliado pelo SGRQ mostrou aumento significativo do escore do domínio atividade $(52 \pm 21$ vs $60 \pm 22 \%$; p<0,001) e do escore total $(42 \pm 19$ vs $44 \pm 19 \%$; $=0,041$ ) do SGRQ (Figura 7).

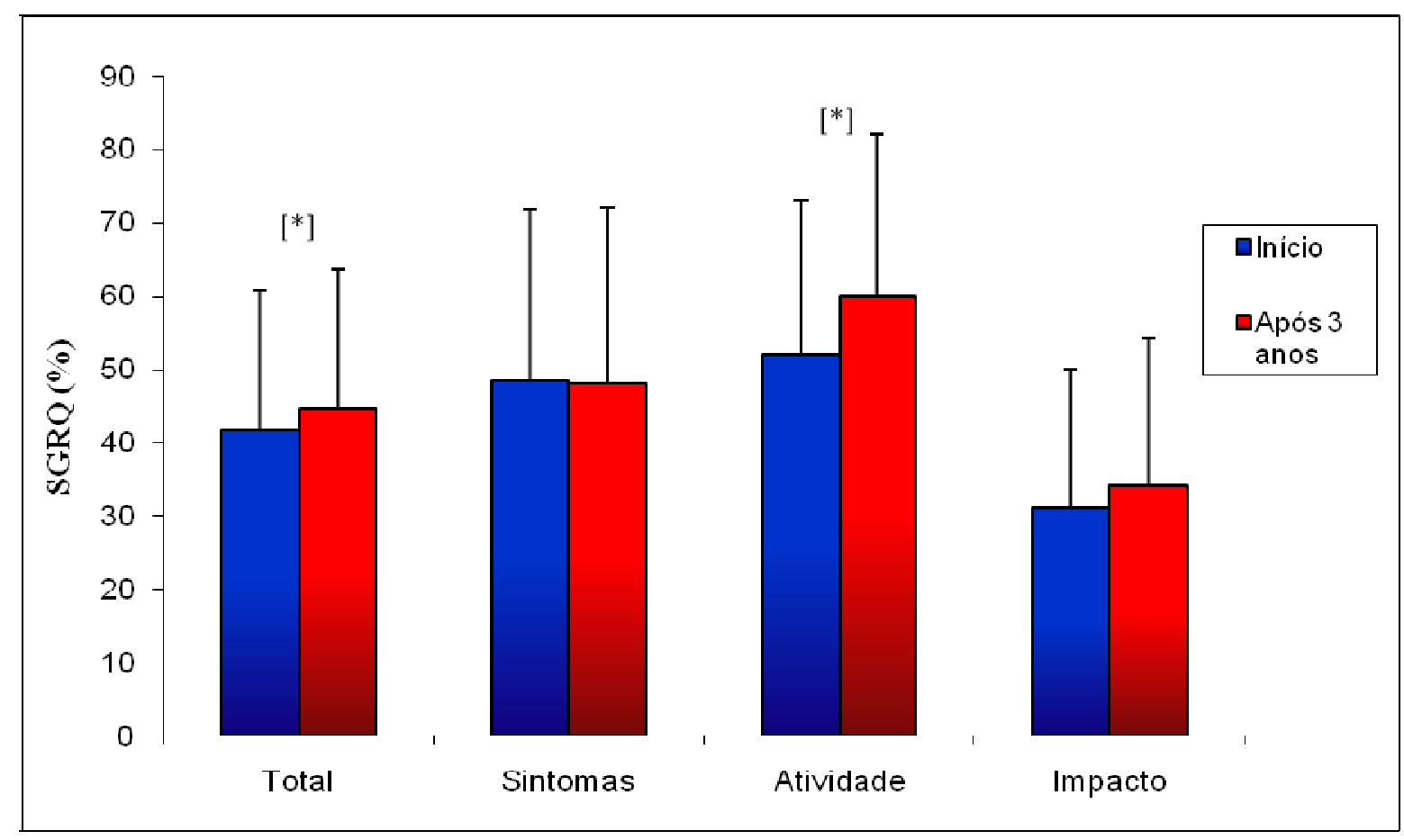

Figura 7. Evolução dos domínios do SGRQ no período de três anos; * p<0,05 
Quando foi avaliada a porcentagem dos pacientes que apresentaram piora ou melhora clinicamente significativa $(\geq 4 \%)$ nos domínios do SGRQ, observamos que no escore total $28 \%$ dos pacientes melhoraram e $51 \%$ pioraram, no domínio sintomas $41 \%$ melhoraram e $44 \%$ pioraram, no domínio atividade $28 \%$ melhoraram e $58 \%$ pioraram e no domínio impacto $30 \%$ melhoraram e $42 \%$ pioraram. A representação gráfica destes resultados está na Figura 8. A porcentagem de pacientes que não tiveram mudança clinicamente significativa no escore total foi de $21 \%$, no domínio sintomas $15 \%$, no domínio atividade $14 \%$ e no domínio impacto foi de $28 \%$.

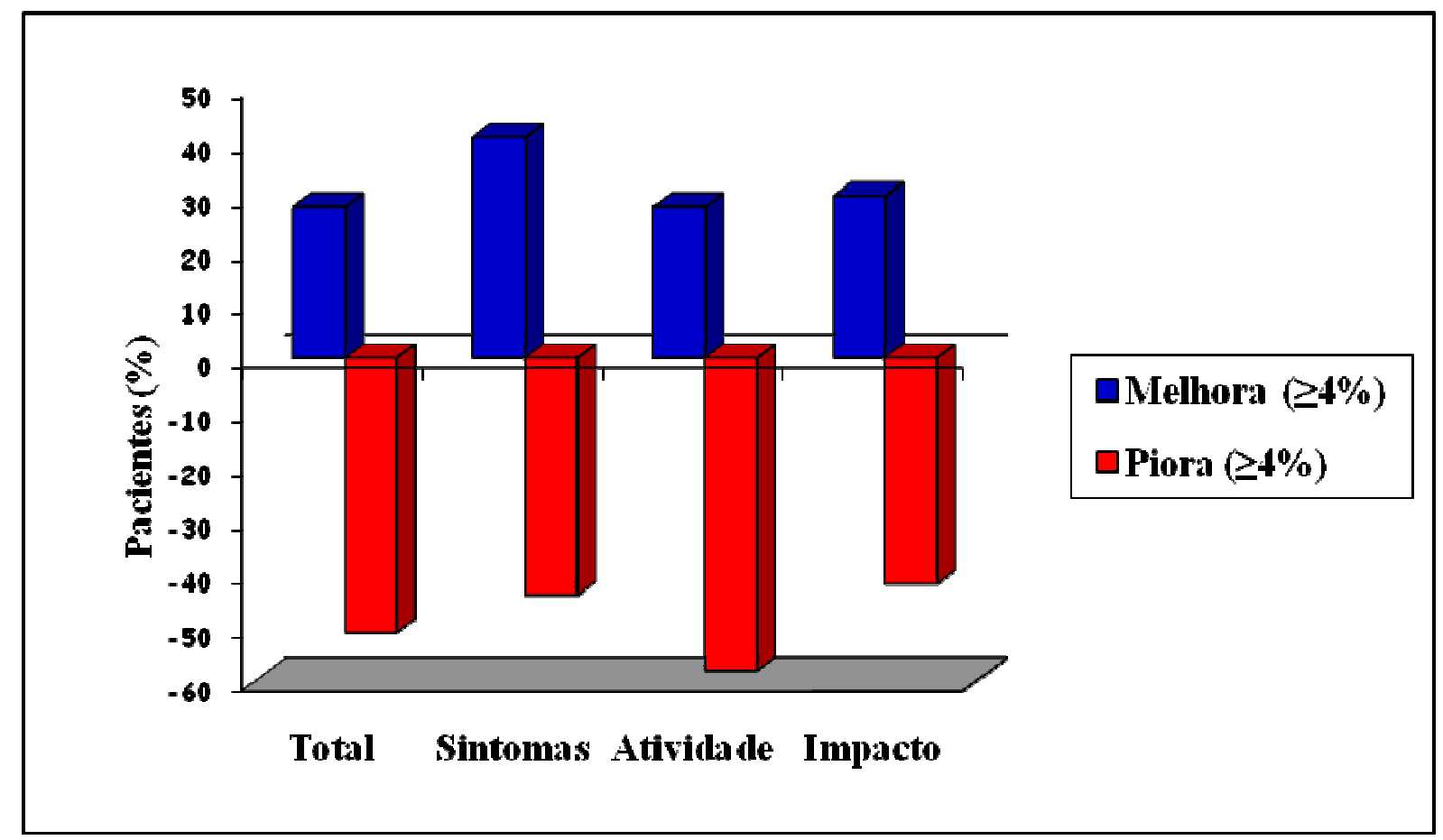

Figura 8. Porcentagem dos pacientes que apresentaram piora ou melhora clinicamente significativa ( $\geq 4 \%$ ) do SGRQ após três anos 
$\mathrm{Na}$ análise de regressão logística múltipla, a variação no Índice BODE foi preditora da piora clinicamente significativa no escore total do SGRQ (Odds de 1,48 - 95\% IC de 1,04 a 2,09), como representado na Figura 9.

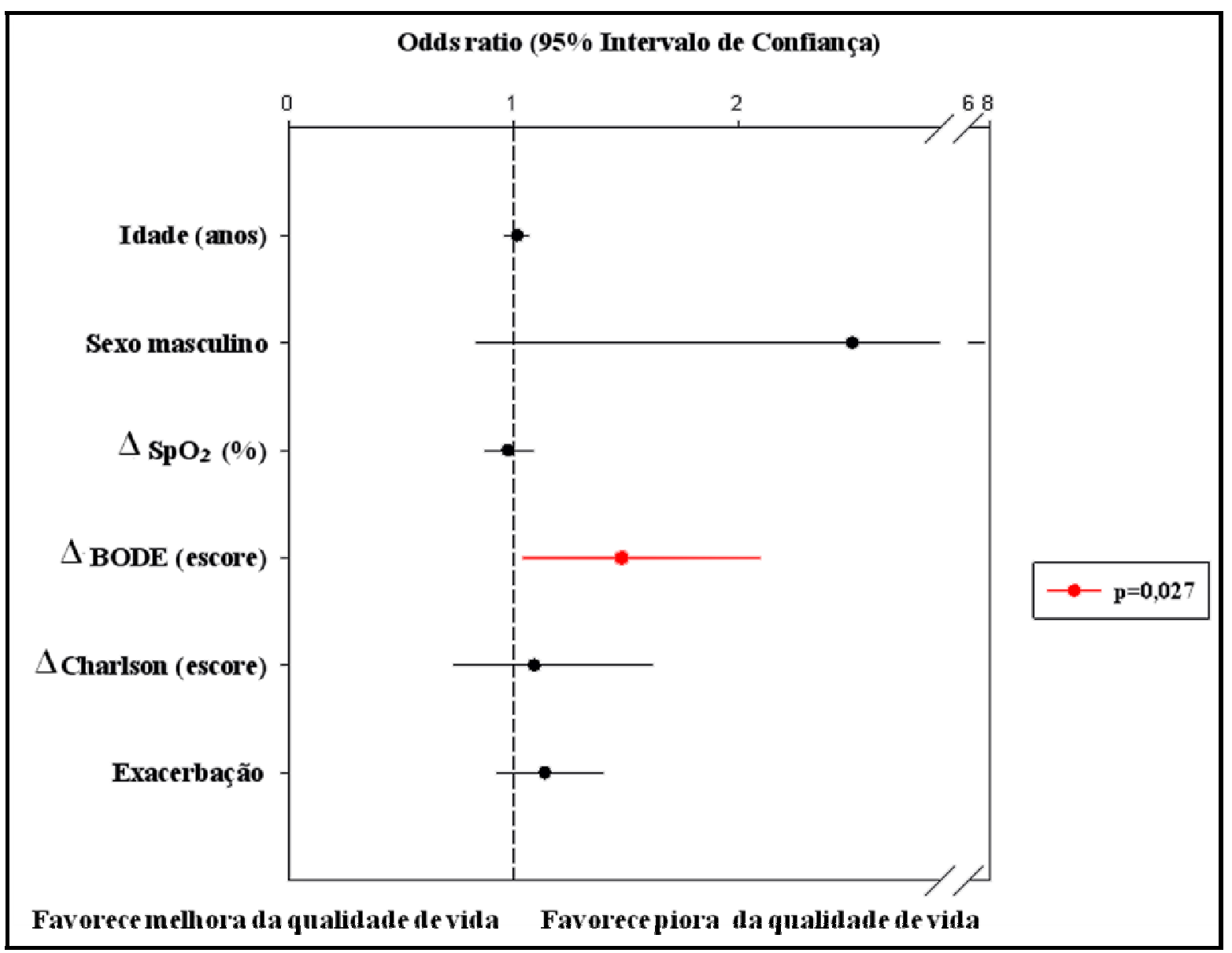

$\Delta$ : valores da avaliação final - valores da avaliação inicial; $\mathrm{SpO}_{2}$ : oximetria de pulso; Exacerbação: número de exacerbações por paciente no período de três anos.

Figura 9. Análise de regressão logística múltipla para avaliar os preditores de piora ou melhora clinicamente significativa $(\geq 4 \%)$ no escore total do SGRQ

Quando o índice BODE foi substituído pelas variáveis que o constitui (IMC, $\mathrm{MRC}, \mathrm{VEF}_{1}$ e DP6), a variação do $\mathrm{MRC}$ foi preditora da piora clinicamente significativa no escore total do SGRQ (Odds de 2,73 - 95\% IC de 1,47 a 5,07) (Figura 10). 


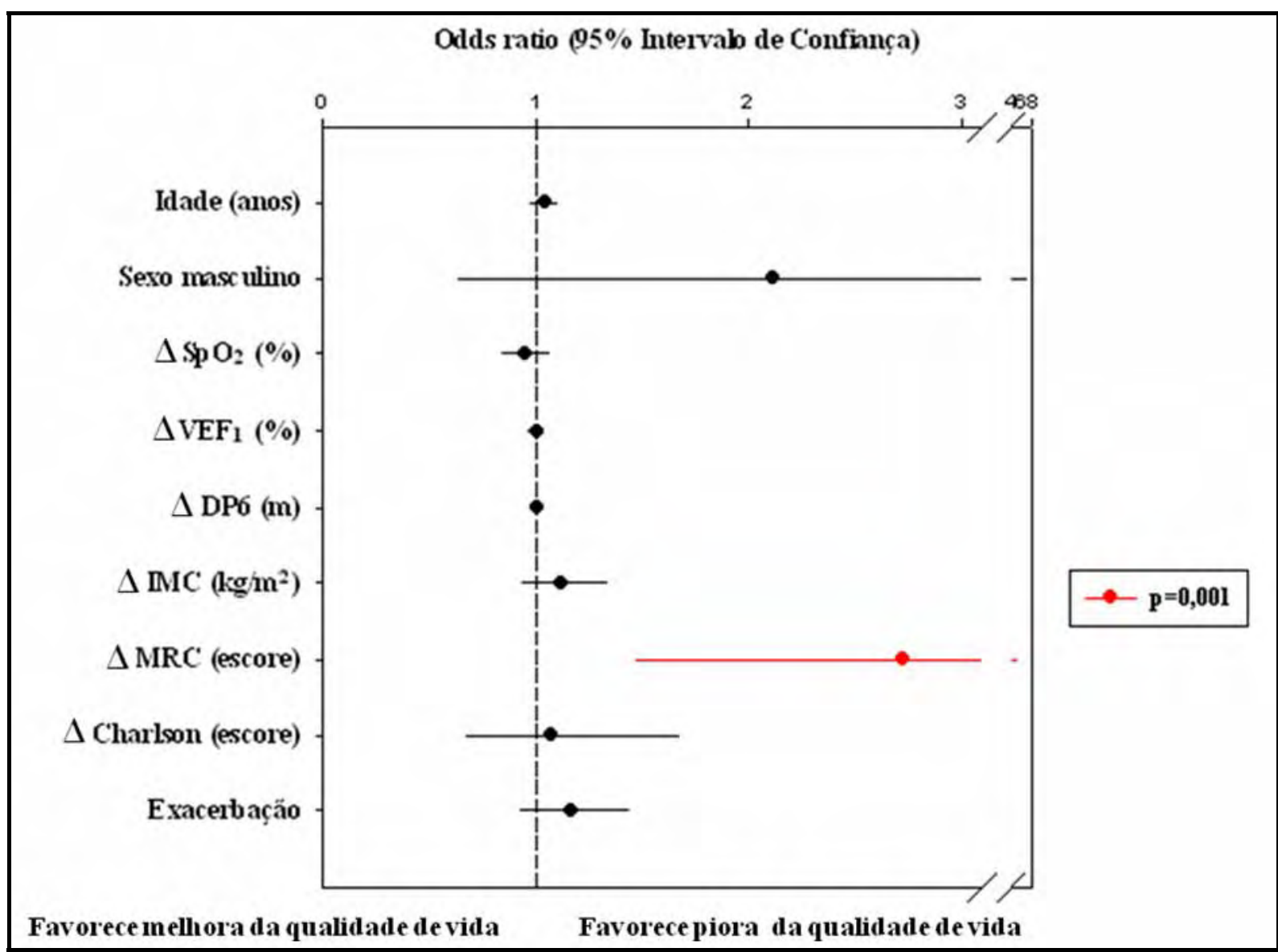

$\Delta$ : valores da avaliação final - valores da avaliação inicial; $\mathrm{SpO}_{2}$ : oximetria de pulso; $\mathrm{VEF}_{1}$ : volume expiratório forçado no primeiro segundo; DP6: distância percorrida em seis minutos; IMC: índice massa do corpo; MRC: Medical Research Council; Exacerbação: número de exacerbações por paciente no período de três anos.

Figura 10. Análise de regressão logística múltipla para avaliar os preditores de piora ou melhora clinicamente significativa $(\geq 4 \%)$ no escore total do SGRQ

No domínio atividade do SGRQ, a variação no Índice BODE foi preditora da piora clinicamente significativa (Odds de 1,45 - 95\% IC de 1,04 a 2,03). No segundo modelo, com a substituição do Índice BODE pelas variáveis IMC, MRC, VEF 1 e DP6, a variação do MRC foi preditora da piora clinicamente significativa nesse domínio (Odds de 1,67 - 95\% IC de 1,04 a 2,03). Nos domínios sintomas e impacto do SGRQ, não foram identificadas variáveis preditoras da piora ou melhora clinicamente significativa. 
Discussão 


\section{DISCUSSÃO}

De acordo com nosso conhecimento, este estudo foi o primeiro que avaliou as modificações no índice BODE e sua associação com a evolução da qualidade de vida relacionada à saúde no período de três anos em pacientes com DPOC leve a muito grave. Nossos resultados também reforçam achados prévios sobre a importância da idade, da troca gasosa e do índice BODE como preditores da frequência de exacerbações e de mortalidade. Além disso, confirmam que diminuição da tolerância ao exercício e aumento da sensação de dispneia podem ocorrer apesar da estabilidade da obstrução das vias aéreas e da composição do corpo. Em conjunto, estes dados reforçam o conceito que o acompanhamento dos pacientes com DPOC deve incluir outros indicadores além daqueles relacionados com a obstrução das vias aéreas.

$\mathrm{Na}$ amostra de 95 pacientes avaliada no momento basal e após três anos verificamos que houve piora significativa no domínio atividade e no escore total do SGRQ ao final do acompanhamento. Nosso resultado está de acordo com o estudo de Oga et al., (2007), o qual mostrou piora da qualidade de vida verificada por meio do aumento dos escores dos domínios atividade, impacto e do escore total do SGRQ, após cinco anos de acompanhamento. Na análise de regressão logística múltipla, verificamos que a variação do índice BODE foi preditora da piora clinicamente significativa do SGRQ no escore total e no domínio atividade. Não encontramos estudos longitudinais anteriores que avaliaram a associação entre a variação do índice BODE e da qualidade de vida relacionada à saúde. Entretanto, estudos transversais mostram que o Índice BODE apresenta maior associação com o comprometimento da qualidade de vida quando comparado à gravidade da doença classificada pelo GOLD (Ong et al., 2006; Medina Amorós et al., 2009). Em estudo transversal, Ong et al., (2006) avaliaram 100 pacientes com DPOC e verificaram que maiores escores do SGRQ estavam associados com maiores quartis do índice BODE.

Em nosso estudo, ao substituir o índice BODE pelo $\mathrm{VEF}_{1}$, IMC, MRC e DP6 na análise de regressão logística múltipla, encontramos que a variação do MRC foi preditora da piora clinicamente significativa no escore total e no domínio atividade. Em estudos transversais e longitudinais, a intensidade da dispneia é reportada como preditora da qualidade de vida (Dourado et al., 2004; Schelecht et al., 2005, Oga et al., 2007). Em estudo longitudinal, a mudança no escore total do SGRQ apresentou correlação com as mudanças na percepção de dispneia $(\mathrm{r}=0,59)$, avaliada pelo MRC, e também com a mudança nos valores do $\mathrm{VEF}_{1}$ em porcentagem dos valores previstos embora com valores menores de $r(r=0,44)(\mathrm{Oga}$ 
et al., 2007). No mesmo estudo, verificou-se correlação da variação do escore total do SGRQ com os sintomas de ansiedade $(\mathrm{r}=0,55)$ e depressão $(\mathrm{r}=0,56)$ e com o consumo de oxigênio $(\mathrm{r}=0,20)$. No entanto, os autores não avaliaram a influência do índice BODE e das exacerbações nas modificações da qualidade de vida.

Estes dados reforçam a importância de medidas terapêuticas para controle da dispneia como instrumento para manter ou melhorar a qualidade de vida relacionada à saúde de pacientes com DPOC. Dentre estas medidas podem ser incluídas o manejo farmacológico e principalmente a reabilitação pulmonar (Ries et al., 2007).

$\mathrm{O} \mathrm{VEF}_{1}$ ainda é a principal variável determinante da presença e da gravidade da DPOC e também é utilizado para avaliar a eficácia de diferentes modalidades de tratamento (Fabbri et al., 2006). Em nosso estudo, o valor do $\mathrm{VEF}_{1}$, em litros, piorou e os valores em porcentagem do previsto não apresentaram mudanças significativas durante $o$ acompanhamento. A diminuição, em litros, apresentada como mediana ( $1^{\circ}$ e $3^{\circ}$ quartil), foi de 0,061 (0,04-0,185 1) com variação de 5,36\% (2,79-14,6\%), e; portanto, não representa uma diferença clinicamente significativa (ATS, 2005). Apesar da estabilidade da obstrução das vias aéreas e da composição do corpo, a tolerância ao exercício diminuiu e a sensação de dispneia aumentou durante o período de estudo. Em média observamos diminuição significativa da capacidade funcional de exercício e, em 31 deles (32\%), a piora foi clinicamente significativa (>54 metros), sendo que 18 destes pacientes (58\%) apresentavam doença grave ou muito grave. Estes resultados estão de acordo com o estudo de Casanova et al., (2007), que acompanhou a evolução de 100 pacientes com DPOC leve a muito grave durante o período de cinco anos e mostrou que houve declínio anual da DP6 e que a proporção de pacientes com diminuição clinicamente significativa foi maior nos pacientes com $\mathrm{VEF}_{1}<50 \%$ dos valores previstos. Estes dados mais uma vez reforçam a importância da inclusão da reabilitação pulmonar no tratamento de pacientes com DPOC (Ries et al., 2007).

Outro sintoma relacionado à gravidade da DPOC que apresentou piora significativa durante o acompanhamento foi a intensidade de dispneia. Houve aumento significativo da sensação de dispneia avaliada por meio dos escores do BDI e do MRC. No estudo de Mahler et al., (1995), 76 pacientes foram acompanhados durante dois anos e verificou-se que apesar da melhora da função pulmonar, o escore de dispneia avaliado pelo Transition Dyspnea Index (TDI) aumentou significativamente. Em contrapartida, estudo de Lareau et al., (1999) mostrou que os valores médios do $\mathrm{VEF}_{1}$ em porcentagem dos valores previstos reduziram significativamente e os escores da dispneia não se alteraram após 5 anos de acompanhamento em 34 pacientes com DPOC. De acordo com nossos resultados, Oga et 
al., (2007) verificaram piora significativa da dispneia, avaliada pelo MRC, no período de cinco anos de acompanhamento. Em resumo, nossos dados reforçam o conceito de que as modificações da sensação de dispneia ocorrem independentemente das alterações observadas na obstrução das vias aéreas avaliada pelo $\mathrm{VEF}_{1}$. Portanto, a avaliação da dispneia no acompanhamento da DPOC é fundamental e deve ser realizada independentemente do acompanhamento por espirometria de acordo com as recomendações das diretrizes brasileiras e internacionais (Jardim et al., 2004; Fabbri et al., 2006).

Nossos resultados não mostraram alteração significativa na composição corporal após três anos de acompanhamento. Prescott et al., (2002) avaliaram 1612 pacientes com DPOC, sendo 736 mulheres e 876 homens e relataram que a perda de peso média foi maior em pacientes com doença grave e muito grave quando comparado com pacientes com doença leve e moderada após cinco anos de acompanhamento. A proporção de pacientes que tiveram perda de peso ( $>1$ unidade no IMC) foi $35,3 \%$ em homens e $27,4 \%$ em mulheres com DPOC grave e muito grave. Em nosso estudo, a prevalência de desnutrição (IMC $<21 \mathrm{~kg} / \mathrm{m}^{2}$ ) no momento basal (20\%) foi similar à descrita anteriormente em estudos realizados em nosso meio e na literatura internacional (Dourado et al., 2006; Schols et al., 1993; Engelen et al., 1994). A prevalência de depleção de MMC no momento basal foi em média de $40 \%$ sem diferença entre as classes de gravidadees da doença. Na literatura a prevalência de depleção de MMC varia em 18\% (Schols et al., 1993; Engelen et al., 1994) a 52\% (Steuten et al., 2006) na dependência do grupo de pacientes, da gravidade da doença e do critério de depleção empregado. Na população estudada, o estado nutricional não variou significativamente durante o período de três anos. Entretanto, é importante ressaltar que $11 \%$ da amostra inicialmente avaliada morreu e $17 \%$ dos pacientes não foram reavaliados durante o período do estudo e, portanto, conclusões definitivas sobre a importância das alterações nutricionais na evolução da DPOC não podem ser estabelecidas a partir da amostra avaliada.

Nossos resultados mostram que durante o período do estudo, cinco pacientes apresentaram classificações mais graves da DPOC, de acordo com o GOLD e nove pacientes de acordo com as classes do índice BODE. Além disso, o índice BODE aumentou significativamente no período, o que reforça a importância da avaliação multidimensional no acompanhamento de pacientes com DPOC. A principal variável determinante do aumento do índice BODE foi a dispneia, avaliada pelo MRC. Em nossos dados, apesar da diminuição média significativa da DP6, a proporção de pacientes que tiveram aumento do índice BODE pela alteração da DP6 foi baixa, uma vez que os valores médios da DP6 foram maiores que 365 metros. Estudo de Pitta et al., (2009) confirma esse resultado ao relatar maior atividade 
física diária em pacientes brasileiros quando comparados a pacientes austríacos (Pitta et al., 2009).

Em 124 pacientes foram avaliados os preditores de mortalidade no período de três anos. A gravidade da doença, classificada pelo GOLD, não foi selecionada como preditora de mortalidade no estudo. No entanto, o aumento de um quartil no índice BODE foi associado com risco de mortalidade três vezes maior. O índice BODE foi descrito inicialmente por Celli et al., (2004) e engloba preditores independentes de mortalidade, refletindo não apenas o comprometimento na função pulmonar, mas também consequências sistêmicas da doença. $\mathrm{O}$ índice foi validado em uma coorte de 625 pacientes, avaliados a cada seis meses por pelo menos dois anos ou até o óbito. Os autores encontraram que o índice foi melhor preditor de mortalidade do que os valores de $\mathrm{VEF}_{1}$. Consistente com nosso resultado, Martinez et al., (2008) confirmaram o valor preditivo de mortalidade do índice BODE em 610 pacientes com DPOC grave em tratamento medicamentoso e 608 tratados cirurgicamente. Os autores verificaram que aumento no Índice BODE maior que um ponto do momento basal para 6, 12 e 24 meses, foi associado com maior mortalidade nos dois grupos. A idade avançada foi também identificada como fator de risco para mortalidade em nosso estudo. Resultado este, previamente reportado no estudo de Anthonisen et al., (1986), no qual foram acompanhados 985 pacientes com DPOC por três anos e a idade e os valores previstos do $\mathrm{VEF}_{1}$ foram preditores independentes de mortalidade. No entanto, não encontramos associação da gravidade da doença, classificada pelos valores de $\mathrm{VEF}_{1}$, com a mortalidade.

No período de acompanhamento, o índice BODE foi também preditor para frequência de exacerbações. Estudos recentes mostraram que o índice BODE foi sensível para avaliar o impacto das exacerbações, para monitorar a progressão da DPOC e foi melhor preditor para número e gravidade das exacerbações do que os valores do $\mathrm{VEF}_{1}$ (Cote et al., 2007; Marin et al., 2009). Cote et al., (2007) avaliaram 205 pacientes com DPOC e verificaram que o valor do Índice BODE aumentou durante a exacerbação em relação ao calculado na avaliação inicial $(4,2 \pm 2,1$ vs 3,57 $\pm 2,3)$. O índice BODE permaneceu 0,8 pontos acima dos valores basais após um ano e 1,1 pontos maior após dois anos de acompanhamento. No estudo de estudo de Marin et al., (2009), o índice BODE foi preditor para número de exacerbações e pacientes com escore do BODE > 7 tiveram exacerbações com necessidade de hospitalização. Em contrapartida, Ong et al., (2005) mostraram que pacientes na classe 2 do BODE tiveram risco duas vezes maior para hospitalização do que pacientes na classe 1 , porém pacientes na classe 3 apresentaram menor risco para hospitalização quando comparados aos pacientes da classe 1. 
Em nosso estudo, a gravidade da doença, classificada pelo GOLD, foi também associada à exacerbação da DPOC. Entretanto, estudo publicado recentemente mostrou que o índice BODE e a classificação da gravidade, de acordo com o GOLD não foram selecionados como preditores de exacerbação em análise de regressão logística múltipla ajustada (Faganello et al., 2010). A diferença desses resultados pode ser devido ao período dos dois estudos, uma vez que acompanhamos os pacientes por três anos e no estudo de Faganello et al., os preditores de exacerbação foram estudados em apenas um ano.

Outra variável associada com a frequência de exacerbação foi a $\mathrm{SpO}_{2}$. Por meio da análise de regressão, evidencia-se que pacientes hipoxêmicos têm maior risco de apresentar exacerbação. Estudos prévios mostraram que a hipoxemia, principalmente quando não corrigida, está associada à hospitalização por exacerbação da doença (Kessler et al., 1999, Garcia-Aymerich et al., 2001). No estudo de Kessler et al., (1999), a hipoxemia esteve associada com o risco de hospitalização apenas na análise univariada. Risco aumentado de hospitalização por exacerbação entre os pacientes que apresentaram hipoxemia e não estavam recebendo suplementação de oxigênio foi descrito por Garcia-Aymerich et al., (2001). Nossos dados também confirmaram os resultados do estudo de Faganello et al., (2010), no qual menores valores de $\mathrm{SpO}_{2}$ foram fatores de risco para exacerbação no período de um ano de acompanhamento, independentemente da gravidade da doença classificada pelo GOLD ou das classes do BODE.

No modelo de regressão de Poisson, no qual o índice BODE foi substituído pelas variáveis que o constitui, menores valores do $\mathrm{VEF}_{1}$ e do IMC foram preditores de exacerbação. De acordo com nosso estudo, Donaldson et al., (2002) relataram que pacientes com exacerbações frequentes apresentaram menores valores de $\mathrm{VEF}_{1}$ no momento basal e maior declínio anual do $\mathrm{VEF}_{1}$ comparado com os pacientes com exacerbações infrequentes. No estudo de Niewohner et al., (2007), menores valores de $\mathrm{VEF}_{1}$ foram fatores de risco independentes para exacerbações e hospitalizações, decorrentes de exacerbação, em 1829 pacientes com DPOC moderada a muito grave acompanhados durante seis meses. Menores valores do IMC também foram descritos anteriormente como fatores de risco para exacerbação (Kessler et al., 1999, Hallin et al., 2006). Em estudo prospectivo multicêntrico, a influência do estado nutricional foi avaliada no risco de nova exacerbação após alta hospitalar em pacientes internados devido à agudização da DPOC (Hallin et al., 2006). Os autores verificaram que o baixo peso (IMC $<20 \mathrm{~kg} / \mathrm{m}^{2}$ ), na avaliação inicial, e a perda de peso durante o período de um ano de acompanhamento foram fatores de risco independentes para ocorrência de nova exacerbação. 
Em nosso estudo, a anemia, caracterizada pelos valores do hematócrito, foi associada com risco de exacerbação de 2,5 vezes maior. Uma possível explicação para esse achado seria que a anemia está relacionada à presença de inflamação e é observada em pacientes com concomitante infecção e doenças inflamatórias. Explicação esta que condiz com o estado inflamatório sistêmico da DPOC e com o aumento dos mediadores inflamatórios durante as exacerbações da doença (Gan et al., 2004; Hurst et al., 2006). John et al., (2005) verificaram que pacientes com DPOC anêmicos apresentaram níveis séricos aumentados da Proteína C-Reativa e resistência a níveis séricos elevados do hormônio eritropoetina. $\mathrm{O}$ aumento dos mediadores inflamatórios interfere no mecanismo da eritropoiese, inibindo a produção e o efeito da eritropoetina e do ferro na medula óssea. Após o desenvolvimento da anemia, ocorre autorregulação da eritropoetina para manter a homeostase. No entanto, pacientes com DPOC anêmicos não respondem ao aumento dos níveis de eritropoetina. Esse mecanismo é similar em outras doenças e explica a fisiopatologia da anemia em doenças crônicas (John et al., 2005). No mesmo estudo, não foi observada associação da anemia com perda de peso e caquexia, indicando que seu desenvolvimento é independente dos fatores nutricionais (John et al., 2005). No estudo de Chambellan et al., (2005), dos 2524 pacientes com DPOC muito grave em uso de ODP, hematócrito baixo foi associado com maior taxa de admissão e maior tempo de hospitalização quando comparado com pacientes não anêmicos. No entanto, não encontramos estudos mostrando a influência da anemia no risco de exacerbação da DPOC em pacientes com doença de diferentes gravidades.

Em resumo, nosso estudo trouxe uma contribuição inédita na literatura referente à associação entre as alterações do índice BODE e a qualidade de vida relacionada à saúde. Além disso, mostrou que independentemente da evolução da obstrução das vias aéreas e da composição corporal, ocorre piora de outras manifestações sistêmicas da DPOC. Estes achados em pacientes brasileiros com DPOC reforçam a proposta internacional de uma nova classificação de gravidade da doença que contemple essas modificações. 
Conclusões 


\section{CONCLUSÕES}

A qualidade de vida relacionada à saúde piorou significativamente nos três anos de acompanhamento e as mudanças no índice BODE foram preditoras da piora.

A influência do aumento nos quartis do índice BODE e da idade na mortalidade mostra a importância das características demográficas do paciente e das manifestações sistêmicas da doença para o prognóstico.

Além da importância dos preditores clássicos de exacerbação (BODE, menores valores de $\mathrm{SpO}_{2}, \mathrm{VEF}_{1}$, IMC) valores baixos de hematócrito também foram identificados como preditores da exacerbação em pacientes com DPOC. 
Referências 


\section{REFERÊNCIAS *}

American Thoracic Society Statement. Standardization of Spirometry - Update. Am Rev Respir Dis. 1987; 136:1285-98.

American Thoracic Society. ATS/ERS Task Force: Standardization of lung function testing: standardization of spirometry. Eur Respir J. 2005; 26:319-38.

Anthonisen NR, Wright EC, Hodgkin JE. Prognosis in Chronic Obstructive Pulmonary Disease. Am Rev Respir Dis. 1986; 133:14-20.

Borg G. Escala CR10 de Borg. In: Borg G. Escalas de Borg para dor e esforço percebido. São Paulo: Manole; 2000. p. 43-7.

Boushy SF, Thompson HK, North LB, Beale AR, Snow TR. Prognosis in Chronic Obstructive Pulmonary-Disease. Am Rev Respir Dis. 1973; 108:1373-83.

Burge PS, Calverley PMA, Jones PW, Spencer S, Anderson JA, Maslen TK. Randomised, double blind, placebo controlled study of fluticasone propionate in patients with moderate to severe chronic obstructive pulmonary disease: the ISOLDE trial. BMJ. 2000; 320:1297-303.

Casanova C, Cote CG, Marin JM, Torres JP, Aguirre-Jaime A, Mendez R, et al. The 6-min walking distance: long-term follow up in patients with COPD. Eur Respir J. 2007; 29:535-40.

Celli BR, Cote CG, Marin JM, Casanova C. The body-mass index, airflow obstruction, dyspnea, and exercise capacity index in chronic obstructive pulmonary disease. $\mathrm{N}$ Engl $\mathbf{J}$ Med. 2004; 350:1005-12.

\footnotetext{
* International Committee of Medical Journal Editors. Uniform Requirements for Manuscripts Submitted to Biomedical Journal: sample references.[homepage on the Internet]. Bethesda: U.S. National Library of Medicine; 2003[last updated 2009 May 14]. Available from:http://www.nlm.nih.gov/bsd/uniform_requirements.html
} 
Chambellan A, Chailleux E, Similowski T and the Antadir Observatory Group. Prognostic value of the hematocrit in patients with severe COPD receiving long term oxygen therapy. Chest. 2005; 128:1201-8.

Charlson M, Szatrowski TP, Peterson J, Gold J. Validation of a Combined Comorbidity Index. J Clin Epidemiol. 1994; 47:1245-51.

Coleta KD, Silveira LV, Lima DF, Rampinelli EA, Godoy I, Godoy I. Predictors of first-year survival in patients with advanced COPD treated using long-term oxygen therapy. Respir Med. 2008; 102:512-8.

Connors AF, Dawson NV, Thomas C, Harrel FE Jr, Desbiens N, Fulkerson WJ, et al. Outcomes following acute exacerbation of severe chronic obstructive lung disease. Am J Respir Crit Care Med. 1996; 154:959-67.

Cote CG, Dordelly LJ, Dordelly LJ, Celli BR. Impact of COPD exacerbations on patientcentered outcomes. Chest. 2007; 131:696-704.

Cote CG, Zilberberg MD, Mody SH, Dordelly LJ, Celli B. Haemoglobin level and its clinical impact in a cohort of patients with COPD. Eur Respir J. 2007; 29:923-9

Crapo RO, Casaburi R, Coates AL, Enright PL, Maclntyre NR, Mckay RT, et al. ATS statement: Guidelines for the six-minute walk test. Am J Respir Crit Care Med. 2002; $166: 111-7$.

DATASUS [Internet]. Sistema de informação sobre mortalidade. Brasília: Ministério da Saúde; 2008 [Acesso 18 set 2008]. Disponível em: http:/www.datasus.gov.br .

Dewan NA, Rafique S, Kanwar B, Satpathy H, Ryschon K, Tillotson GS, et al. Acute exacerbation of COPD - Factors associated with poor treatment outcome. Chest. 2000; 117:662-71. 
Donaldson GC, Seemungal TAR, Bhowmik A, Wedzicha JA. Relationship between exacerbation frequency and lung function decline in chronic obstructive pulmonary disease. Thorax. 2002; 57:847-52.

Dourado VZ, Antunes LCO, Carvalho LR, Godoy I. Influência de características gerais na qualidade de vida em pacientes com doença pulmonar obstrutiva crônica. J Bras Pneumol. 2004; 30:207-14.

Dourado VZ, Antunes LC, Tanni SE, Paiva SA, Padovani CR, Godoy I. Relationship of upper-limb and thoracic muscle strength to 6-min walk distance in COPD patients. Chest 2006; 129:551-7.

Engelen MPKJ, Schols AMWJ, Baken WC, Wesseling, GJ, Wouters EFM. Nutritional depletion in relation to respiratory and peripheral skeletal muscle function in out-patients with COPD. Eur Respir J. 1994; 7:1793-7.

Fabbri LM, Luppi F, Beghe B, Rabe KF. Update in chronic obstructive pulmonary disease 2005. Am J Respir Crit Care Med. 2006; 173:1056-65.

Faganello MM, Tanni SE, Sanchez FF, Pelegrino NRG, Lucheta PA, Godoy I. BODE index and gold staging as predictors of one-year exacerbation risk in chronic obstructive pulmonary disease. Am J Med Sci. 2010; 339:10-4.

Gan WQ, Man SFP, Senthilselvan A, Sin DD. Association between chronic obstructive pulmonary disease and systemic inflammation: a systematic review and a meta-analysis. Thorax. 2004; 59:574-80.

Garcia-Aymerich J, Monso E, Marrades RM, Escarrabil J, Felez MA, Sunyer J, Anto JM, EFRAM Investigators. Risk factors for hospitalization for a chronic obstructive pulmonary disease exacerbation. EFRAM study. Am J Crit Care Med. 2001; 164:1002-7.

Godoy I, Togashi RH, Geraldo RR, Campana AO. Is chronic hypoxemia in patients with chronic obstructive pulmonary disease associated with more marked nutritional deficienty? A 
study of the fat-free mass evaluated by anthropometry and biolectrical impedance methods. $\mathbf{J}$ Nutr Health Aging. 2000; 4:102-8.

Gray-Donald K, Gibbons L, Shapiro ST, Macklem PT, Martin JG. Nutricional status and mortality in chronic obstructive pulmonary disease. Am J Respir Crit Care Med. 1996; 153:961-6.

Hallin R, Koivisto-Hursti UK, Lindberg E, Janson C. Nutritional status, dietary energy intake and the risk of exacerbations in patients with chronic obstructive pulmonary disease (COPD). Respir Med. 2006; 100:561-7.

Hurst JR, Donaldson GC, Perera WR, Wilkinson TMA, Bilello JA, Hagan GW, et al. Use of plasma biomarkers at exacerbation of chronic obstructive pulmonary disease. Am J Respir Crit Care Med. 2006; 174:867-74.

Jardim JR, Oliveira JA, Nascimento O. II Consenso Brasileiro de DPOC. J Bras Pneumol. 2004; 30: S1-S42.

John M, Hoernig S, Doehner W, Okonko DD, Witt C, Anker SD. Anemia and inflammation in COPD. Chest. 2005; 127:825-9

Kessler R, Faller M, Fourgaut G, Mennecier B, Weintzenblum El. Predictive factors of hospitalization for acute exacerbation in a series of 64 patients with chronic obstructive pulmonary disease. Am J Respir Crit Care Med. 1999; 159:158-64.

Kovelis D, Segretti NO, Probst VS, Lareau SC, Brunetto AF, Pitta F. Validação do Modified Pulmonary Functional Status and Dyspnea Questionnaire e da escala do Medical Research Council para o uso em pacientes com doença pulmonar obstrutiva crônica no Brasil. J Bras Pneumol. 2008; 34:1008-18.

Knudson RJ, Lebowitz MD, Holberg CJ, Burrows B. Changes in the Normal Maximal Expiratory Flow-Volume Curve with Growth and Aging. Am Rev Respir Dis. 1983; 127:72534. 
Kyle UG, Bosaeus I, De Lorenzo AD, Deurenberg P, Elia M, Gomez JM, et al. Bioelectrical impedance analysis principles and methods. Clin Nutr. 2004; 23:1226-43.

Kyle UG, Pichard C, Rochat T, Slosman DO, Fitting J-W, Thiebald D. New bioelectrical impedance formula for patients with respiratory insufficiency: comparison to dual-energy Xray absorptiometry. Eur Respir J. 1998; 12:960-6.

Laaban JP, Kouchakji B, Dore M-F, Orvoen-Frija E, Davi P, Rochemaure J. NutritionalStatus of Patients with Chronic Obstructive Pulmonary-Disease and Acute RespiratoryFailure. Chest. 1993; 103:1362-8.

Landbo C, Prescott E, Lange P, Vestbo J, Almdal TP. Prognostic value of nutritional status in chronic obstructive pulmonary disease. Am J Respir Crit Care Med. 1999; 160:1856-61.

Lareau SC, Meek PM, Press D, Anholm JD, Roos PJ. Dyspnea in patients with chronic obstructive pulmonary disease: does dyspnea worsen longitudinally in the presence of declining lung function? Heart Lung. 1999; 28:65-73.

Mahler DA, Tomlinson D, Olmstead EM, Tosteson AN, O'Connor GT. Changes in dyspnea, health status, and lung function in chronic airway disease. Am J Respir Crit Care Med. 1995; 151:61-5.

Mahler DA, Weinberg DH, Wells CK, Feinstein AR. The measurement of dyspnea: contents, inter-observer agreement, and physiologic correlates of two new clinical indexes. Chest. $1984 ; 85: 751-8$.

Marin JM, Carrizo SJ, Casanova C, Martinez-Camblor P, Soriano JB , Agusti AGN, et al. Prediction of risk of COPD exacerbations by the BODE index. Respir Med. 2009; 103:373-8.

Martinez FJ, Foster G, Curtis JL, Criner G, Weinmann G, Fishman A, et al. for the NETT Research Group. Predictors of mortality in patients with emphysema and severe airflow obstruction. Am J Respir Crit Care Med. 2006; 173:1326-34. 
Martinez FJ, Han MK, Andrei AC, Wise R, Murray S, Curtis JL, et al. Longitudinal change in the BODE index predicts mortality in severe emphysema. Am J Respir Crit Care Med. 2008; 178:491-9.

Martinez JAB, Padua AI. Dispneia: novos conhecimentos sobre um velho problema. In: Terra Filho M, Fernandes ALG, Stirbulov R. Pnemologia: atualização e reciclagem volume IV. São Paulo: Vivali; 2001. p.1-12.

Medinas Amorós M, Mas-Tous C, Renom-Sotorra F, Rubí-Ponseti M, Centeno-Flores MJ, Gorriz-Dolz MT. Health-related quality of life is associated with COPD severity: a comparison between the GOLD staging and the BODE index. Chron Respir Dis. 2009; 6:7580 .

Menezes AMB, Jardim JR, Pérez-Padilla R, Camelier A, Rosa F, Nascimento O. Prevalence of chronic obstructive pulmonary disease and associated factors: the PLATINO study in São Paulo, Brazil. Cad Saúde Pública. 2005; 21:1565-73.

Miravitlles M, Mayordomo C, Artés M, Sánchez-Agudo L, Nicolau F, Segú JL. Treatment of chronic obstructive pulmonary disease and its exacerbations in general practice. Respir Med. 1999; 93:173-9.

Niewoehner DE, Lokhnygina Y, Rice K, Kuschner WG, Sharafkhaneh A, Sarosi GA, et al. Risk indexes for exacerbations and hospitalizations due to COPD. Chest. 2007; 131:20-8

Nishimura K, Izumi T, Tsukino M, Oga T. Dyspnea is a better predictor of 5-year survival than airway obstruction in patients with COPD. Chest. 2002; 121:1434-40.

Oga T, Nishimura K, Tsukino M, Sato S, Hajiro T, Mishima M. Longitudinal deteriorations in patient reported outcomes in patients with COPD. Respir Med. 2007; 101:146-53.

Ong KC, Earnest A, Lu SJ. A multidimensional grading system (BODE index) as predictor of hospitalization for COPD. Chest. 2005; 128:3810-6. 
Ong KC, Lu SJ, Soh CS. Does the multidimensional grading system (BODE) correspond to differences in health status of patients with COPD? Int J Chron Obstruct Pulmon Dis. 2006; 1:91-6.

Paiva SAR, Godoy I, Vannucchi H, Favaro RM, Geraldo RR, Campana AO. Assessment of vitamin A status in chronic obstructive pulmonary disease patients and healthy smokers. Am J Clin Nutr. 1996; 64:928-34.

Pinto-Plata VM, Cote C, Cabral H, Taylor J, Celli BR. The 6-min walk distance: change over time and value as a predictor of survival in severe COPD. Eur Respir J. 2004; 23:28-33.

Pitta F, Breyer MK, Hernandes NA, Teixeira D, Sant'Anna TJ, Fontana AD, et al. Comparison of daily physical activity between COPD patients from Central Europe and South America. Respir Med. 2009; 103:421-6.

Postma DS, Burema J, Gimeno F, May JF, Smit JM, Steenhuis EJ, et al. Prognosis in severe chronic obstructive pulmonary-disease. Am Rev Respir Dis. 1979; 119:357-67.

Prescott E, Almdal T, Mikkelsen KL, Tofteng CL, Vestbo J, Lange P. Prognostic value of weight change in chronic obstructive pulmonary disease: results from the Copenhagen City Heart Study. Eur Respir J. 2002; 20:539-44.

Renzetti AD, McClemen JH, Litt BD. Veterans Administration Cooperative Study of Pulmonary Function .3. Mortality in relation to respiratory function in chronic obstructive pulmonary disease. Am J Med. 1966; 41:115-29.

Ries AL, Bauldoff GS, Carlin BW, Casaburi R, Emery CF, Mahler DA, et al. Pulmonary Rehabilitation: Joint ACCP/AACVPR Evidence-Based Clinical Practice Guidelines. Chest. 2007; 131:4S-42S.

Roca J, Rabinovich RA. Respiratory function during exercise. In: Saunders GJG, editor. Respir Med. 2003; 158-69. 
Rodriguez-Roisin R. Toward a consensus definition for COPD exacerbations. Chest. 2000; 117:398S-401S.

Schlecht NF, Schwartzman K, Bourbeau J. Dyspnea as clinical indicator in patients with chronic obstructive pulmonary disease. Chron Respir Dis. 2005; 2:183-91.

Schols AM, Soeters PB, Dingemans AM, Mostert R, Frantzen PJ, Wouters EF. Prevalence and characteristics of nutritional depletion in patients with stable COPD eligible for pulmonary rehabilitation. Am Rev Respir Dis. 1993; 147:1151-6.

Schols A, Broekhuizen R, Weling-Scheepers CA, Wouters EF. Body composition and mortality in chronic obstructive pulmonary disease. Am J Clin Nutr. 2005; 82:53-9.

Schols AMWJ. Nutriction in chronic obstructive pulmonary disease. Curr Opin Pulm Med. 2000; 6:110-5.

Schunemann HJ, Griffith L, Jaeschke R, Goldstein R, Stubbing D, Guyatt GH. Evaluation of the minimal important difference for the feeling thermometer and the $\mathrm{St}^{\prime}$ George's Respiratory Questionnaire in patients with airflow obstruction. J Clin Epidemiol. 2003; 56(12):1170-6.

Seemungal TAR, Donaldson GC, Paul EA, Bestall JC, Jeffries DJ, Wedzicha JA. Effect of exacerbation on quality of life in patients with chronic obstructive pulmonary disease. Am $\mathbf{J}$ Respir Crit Care Med. 1998; 157:1418-22.

Sousa TC, Jardim JR, Jones P. Validation of the Saint George Respiratory Questionnaire (SGRQ) in patients with chronic obstructive disease in Brazil. J Bras Pneumol. 2000; 26:11925.

Spencer S, Calverley PM, Burge PS, Jones PW. Impact of preventing exacerbations on deterioration of health status in COPD. Eur Respir J. 2004; 23:698-702. 
Steuten LM, Creutzberg EC, Vrijhoef HJ, Wouters EF. COPD as a multicomponent disease: inventory of dyspnoea, underweight, obesity and fat free mass depletion in primary care. Prim Care Respir J. 2006; 15:84-91.

Vandenbergh E, Woestijne Kp, Gyselen A. Weight Changes in Terminal Stages of Chronic Obstructive Pulmonary Disease - Relation to Function and Prognosis. Am Rev Respir Dis. 1967; 95:556-66.

Vestbo J, Prescott E, Almdal T, Dahl M, Nordestgaard BG, Andersen T, et al. Body mass, fatfree body mass, and prognosis in patients with chronic obstructive pulmonary disease from a random population sample. Am J Respir Crit Care Med. 2006; 173:79-83.

Vitacca M, Clini E, Porta R, Foglio K, Ambrosino N. Acute exacerbations in patients with COPD: Predictors of need for mechanical ventilation. Eur Respir J. 1996; 9:1487-93.

Wang Q, Bourbeau J. Outcomes and health-related quality of life following hospitalization for an acute exacerbation of COPD. Respirology. 2005; 10:334-40.

Wilson DO, Rogers RM, Wright EC, Anthonisen NR. Body weight in chronic obstructive pulmonary disease. The National Institutes of Health Intermittent Positive-Pressure Breathing Trial. Am Rev Respir Dis. 1989; 139:1435-8.

World Health Organization (WHO). Nutritional anemias: Report of a WHO Scientific Group. In:WHO Technical Report Series 405. Geneva: World Health Organization; 1968. p.1-37.

World Health Organization (WHO). WHO report on the global tobacco epidemic, 2008: the MPOWER package [Internet].Geneva: WHO; 2008 [Acesso 20 Ago 2009]. p.14-22. Disponível em: http:/www.who.int/tobacco/mpower/mpower_report_tobacco_crisis_2008.pdf 
Anexos e Apêndices 
Anexo A - Aprovação do Projeto de Pesquisa pelo Comitê de Ética em Pesquisa (CEP) da Faculdade de Medicina de Botucatu (FMB) - UNESP.

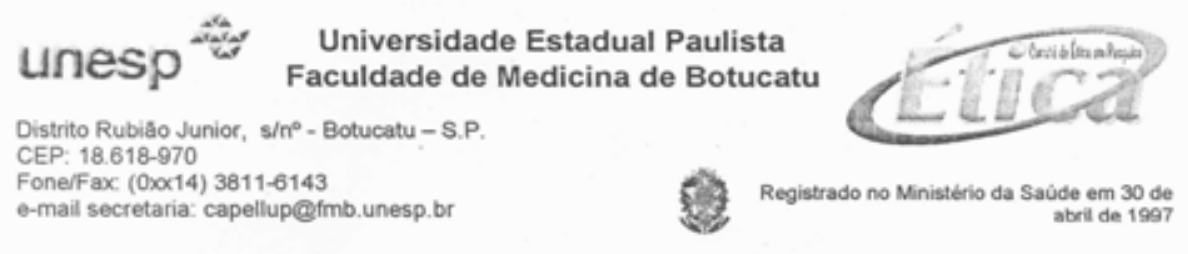

Botucatu, 01 de outubro de 2.007

OF. 390/2007-CEP

llustríssima Senhora

Profa. Dr". Irma de Godoy

Departamento de Clínica Médica da

Faculdade de Medicina de Botucatu

Prezada Dr Irma,

De ordem da Senhora Coordenadora deste CEP, informo que Projeto de Pesquisa "Evoluçāo dos marcadores diagnósticos e prognósticos de pacientes com DPOC no período de três anos" a ser conduzido por Renata Ferrari, orientada por Vossa Senhoria, recebeu do relator parecer favorável, aprovado em reunião de 01 de outubro de 2.007 .

Situação do Projeto: APROVADO. Ao final da execução deste Projeto, apresentar ao CEP "Relatório Final de Atividades".

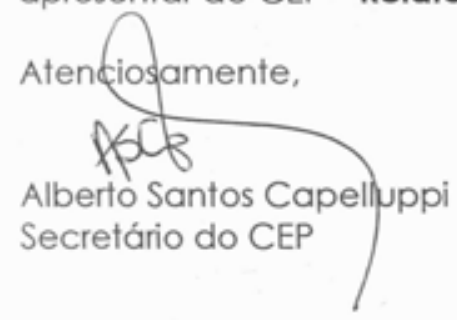




\section{Anexo B - ÍNDICE DE DISPNÉIA BASAL (BDI)}

\section{INCAPACIDADE FUNCIONAL}

( )Grau 4 Nenhuma incapacidade: Capaz de realizar atividades (do cotidiano) e ocupações sem falta de ar.

( )Grau 3 Incapacidade discreta: Prejuízo em pelo menos uma atividade, mas nenhuma atividade completamente abandonada. Redução das atividades no trabalho ou nas atividades usuais (do cotidiano) que parece leve ou não claramente causada pela falta de ar.

( )Grau 2 Incapacidade moderada: O paciente trocou de atividade no trabalho e/ou pelo menos uma atividade do cotidiano pela falta de ar.

( )Grau 1 Incapacidade acentuada: Paciente incapaz de trabalhar e ou abandonou a maioria ou todas as atividades costumeiras pela falta de ar.

( ) Grau 0 Incapacidade muito acentuada: Incapaz de trabalhar e abandonou a maioria ou todas as atividades habituais pela falta de ar.

( ) W Quantidade incerta: O paciente tem incapacidade devido à dispneia, mas a intensidade não pode ser especificada. Os detalhes disponíveis não são suficientes para que a incapacidade seja categorizada.

( ) X Desconhecido: Informação não disponível sobre dispneia e incapacidade.

( ) Y Incapacidade por outras causas que não a dispneia: Por exemplo: problemas neuromusculares ou dor torácica.

\section{MAGNITUDE DA TAREFA}

( )Grau 4 Extraordinária: Tem falta de ar apenas com atividades extraordinárias, tais como carregar cargas muito pesadas no plano, cargas mais leves ao subir ladeiras ou escadas, ou correndo. Nenhuma falta de ar com atividades ordinárias.

( )Grau 3 Maior: Tem falta de ar com atividades tais como subindo ladeira forte, mais de três lances de escada, ou carregando carga no plano.

( )Grau 2 Moderada: Tem falta de ar com atividades moderadas tais como subir uma ladeira suave, menos de três lances de escadas ou carregando uma carga leve no plano.

( )Grau 1 Leve: Tem falta de ar com atividades leves tais como andando no plano, tomando banho, permanecendo em pé ou fazendo compras.

( )Grau 0 Nenhuma tarefa: Falta de ar em repouso, enquanto sentado ou deitado.

( ) W Quantidade incerta: A capacidade de o paciente realizar tarefas está prejudicada devido à dispneia, mas a intensidade não pode ser especificada. Os detalhes não são suficientes para a incapacidade ser categorizada.

( ) X Desconhecido: Ausência da informação disponível relacionada à intensidade da tarefa.

( ) Y Incapacidade por outras razões: Por exemplo: doenças neuromusculares ou dor torácica.

\section{MAGNITUDE DO ESFORÇO}

( )Grau 4 Extraordinário: Tem falta de ar com o maior esforço imaginável. Sem falta de ar com esforços ordinários.

( )Grau 3 Maior: Tem falta de ar com esforço distintamente submáximo mas de proporção maior. Tarefas realizadas sem pausa a menos que requeiram esforço extraordinário.

( )Grau 2 Moderado: Falta de ar com esforço moderado. Tarefas realizadas com pausas ocasionais e precisando de mais tempo do que as pessoas normais.

( )Grau 1 Leve: Tem falta de ar com pouco esforço. Tarefas realizadas com muito esforço ou tarefas mais difíceis realizadas com pausas frequentes, requerendo um tempo de 50 a $100 \%$ maior do que uma pessoa média.

( )Grau 0 Nenhum esforço: Falta de ar em repouso, enquanto sentado ou deitado.

( ) W Quantidade incerta: A capacidade de se exercitar do paciente está prejudicada devido à dispneia, mas a intensidade não pode ser especificada.

( ) X Desconhecido: Ausência de informação disponível relacionada à intensidade do esforço.

( ) Y Incapacidade por outras razões: Por exemplo: doenças neuromusculares ou dor torácica 
Anexo C - ESCALA DE DISPNEIA DE BORG

\section{ESCALA DE BORG}

0 - NENHUM (A)

0,5 - MUITO, MUITO LEVE

1 - MUITO LEVE

2 - LEVE

3 - MODERADA

4 - POUCO INTENSA

5 - INTENSA

6

7 - MUITO INTENSA

8

$9-$

MUITO, MUITO INTENSA

10 - EXAUSTIVO (MÁXIMO) 
Anexo D - Questionário do Hospital Saint George na Doença Respiratória

The St. George's Respiratory Questionnaire - Paul Jones.

\section{Parte 1}

- Nas questões abaixo, assinale aquela que melhor identifica seus problemas respiratórios no último ano.

Obs: Assinale um só espaço para as questões de 1 a 8 :

\begin{tabular}{|c|c|c|c|c|c|}
\hline & $\begin{array}{l}\text { Maioria dos } \\
\text { dias da } \\
\text { semana }(5-7 \\
\text { dias) }\end{array}$ & $\begin{array}{l}\text { Vários dias } \\
\text { da semana } \\
\text { (2-4 dias) }\end{array}$ & $\begin{array}{l}\text { Alguns dias } \\
\text { no mês }\end{array}$ & $\begin{array}{c}\text { Só com } \\
\text { infecções } \\
\text { respiratórias }\end{array}$ & Nunca \\
\hline $\begin{array}{l}\text { 1. Durante o último ano } \\
\text { tossi }\end{array}$ & $\square$ & $\square$ & $\square$ & $\square$ & $\square$ \\
\hline $\begin{array}{l}\text { 2. Durante o último ano } \\
\text { tive catarro }\end{array}$ & $\square$ & $\square$ & $\square$ & $\square$ & $\square$ \\
\hline $\begin{array}{l}\text { 3. Durante o último ano } \\
\text { tive falta de ar }\end{array}$ & $\square$ & $\square$ & $\square$ & $\square$ & $\square$ \\
\hline $\begin{array}{l}\text { 4. Durante o último ano } \\
\text { tive "chiado no } \\
\text { peito" }\end{array}$ & $\square$ & $\square$ & $\square$ & $\square$ & $\square$ \\
\hline
\end{tabular}

5. Durante o último ano, quantas crises graves de problemas respiratórios você teve:

\begin{tabular}{|c|c|c|c|c|}
\hline Mais de 3 & 3 & 2 & 1 & Nenhuma \\
\hline$\square$ & $\square$ & $\square$ & $\square$ & $\square$ \\
\hline
\end{tabular}

6. Quanto tempo durou a pior dessas crises?

(passe para a pergunta 7 se não teve crises graves)

\begin{tabular}{|c|c|c|c|}
\hline 1 semana ou mais & 3 ou mais dias & 1 ou 2 dias & Menos de um dia \\
\hline$\square$ & $\square$ & $\square$ & $\square$ \\
\hline
\end{tabular}

7. Durante o último ano, em uma semana considerada como habitual, quantos dias bons (com poucos problemas respiratórios) você teve:

\begin{tabular}{|c|c|c|c|c|}
\hline Nenhum dia & 1 ou 2 dias & 3 ou 4 dias & Quase todos os dias & Todos os dias \\
\hline$\square$ & $\square$ & $\square$ & $\square$ & $\square$ \\
\hline
\end{tabular}

8. No caso de ter tido "chiado no peito", ele é pior de manhã?

\begin{tabular}{|l|l|}
\hline Não & Sim \\
\hline
\end{tabular}




\section{Parte 2}

\section{- Seção 1}

A. Assinale um só quadrado para descrever a sua doença respiratória:

\begin{tabular}{|c|c|c|c|}
\hline $\begin{array}{c}\text { É o meu maior } \\
\text { problema }\end{array}$ & $\begin{array}{c}\text { Causa-me muitos } \\
\text { problemas }\end{array}$ & $\begin{array}{c}\text { Causa-me alguns } \\
\text { problemas }\end{array}$ & $\begin{array}{c}\text { Não me causa } \\
\text { nenhum problema }\end{array}$ \\
\hline$\square$ & $\square$ & $\square$ & $\square$ \\
\hline
\end{tabular}

B. Em relação ao seu trabalho, assinale um dos quadrados: (passe para a seção 2 se você não trabalha)

Minha doença respiratória obrigou-me a parar de trabalhar Minha doença respiratória interfere com o meu trabalho normal ou já me obrigou a mudar de trabalho

Minha doença respiratória não afeta o meu trabalho

\section{- Seção 2}

As respostas abaixo se referem às atividades que podem provocar falta de ar.

A. Assinale com um "x" o quadrado de cada questão abaixo, indicando a resposta Sim ou Não, de acordo com o seu caso atualmente:

\begin{tabular}{|l|c|c|}
\hline & Sim & Não \\
\hline Sentado ou deitado & $\square$ & $\square$ \\
\hline Tomando banho ou vestindo-se & $\square$ & $\square$ \\
\hline Caminhando dentro de casa & $\square$ & $\square$ \\
\hline Caminhando em terreno plano & $\square$ & $\square$ \\
\hline Subindo um lance de escada & $\square$ & $\square$ \\
\hline Subindo ladeiras & $\square$ & $\square$ \\
\hline Praticando esportes ou jogos que impliquem esforço físico & $\square$ & $\square$ \\
\hline
\end{tabular}

\section{- Seção 3}

A. Assinale com um "x" o quadrado de cada questão abaixo, indicando a resposta Sim ou Não para definir o estado de sua tosse e falta de ar atualmente:

\begin{tabular}{|l|c|c|}
\hline & Sim & Não \\
\hline Minha tosse causa-me dor & $\square$ & $\square$ \\
\hline Minha tosse deixa-me cansado & $\square$ & $\square$ \\
\hline Falta-me o ar quando falo & $\square$ & $\square$ \\
\hline Falta-me o ar quando dobro o corpo para frente & $\square$ & $\square$ \\
\hline Minha tosse ou falta de ar perturba o meu sono & $\square$ & $\square$ \\
\hline Fico exausto com facilidade & $\square$ & $\square$ \\
\hline
\end{tabular}




\section{- Seção 4}

A- Assinale com um "x" o quadrado de cada questão abaixo, indicando a resposta Sim ou Não, para definir o efeito que a doença respiratória tem sobre você:

\begin{tabular}{|l|c|c|}
\hline & Sim & Não \\
\hline Minha tosse ou falta de ar deixam-me envergonhado em público & $\square$ & $\square$ \\
\hline $\begin{array}{l}\text { Minha doença respiratória é inconveniente para a minha família, amigos } \\
\text { ou vizinhos }\end{array}$ & $\square$ & $\square$ \\
\hline Tenho medo ou mesmo pânico quando não consigo respirar & $\square$ & $\square$ \\
\hline Sinto que minha doença respiratória escapa ao meu controle & $\square$ & $\square$ \\
\hline Eu não espero nenhuma melhora da minha doença respiratória & $\square$ & $\square$ \\
\hline $\begin{array}{l}\text { Minha doença debilitou-me física e mentalmente, o que faz com que eu } \\
\text { precise de da ajuda de alguém }\end{array}$ & $\square$ & $\square$ \\
\hline Parece-me perigoso fazer exercício & $\square$ & $\square$ \\
\hline Tudo que faço, parece ser demais para minha capacidade & $\square$ & $\square$ \\
\hline
\end{tabular}

\section{- Seção 5}

A. Assinale com um "x" o quadrado de cada questão abaixo, indicando a resposta Sim ou Não para definir os efeitos da medicação na sua doença respiratória: (passe para a seção 6 se não toma medicamentos)

\begin{tabular}{|l|c|c|}
\hline & Sim & Não \\
\hline Minha medicação não está me ajudando muito & $\square$ & $\square$ \\
\hline Fico envergonhado ao tomar medicamentos em público & $\square$ & $\square$ \\
\hline Minha medicação provoca-me efeitos colaterais desagradáveis & $\square$ & $\square$ \\
\hline Minha medicação interfere muito com meu dia a dia & $\square$ & $\square$ \\
\hline
\end{tabular}

\section{- Seção 6}

A. Assinale com um "x" o quadrado de cada questão abaixo, indicando a resposta Sim ou Não para indicar as atividades que podem ser afetadas pela sua respiração:

\begin{tabular}{|l|c|c|}
\hline & Sim & Não \\
\hline Levo muito tempo para lavar-me ou vestir-me & $\square$ & $\square$ \\
\hline $\begin{array}{l}\text { Demoro muito tempo ou não consigo tomar banho de chuveiro ou na } \\
\text { banheira }\end{array}$ & $\square$ & $\square$ \\
\hline $\begin{array}{l}\text { Ando mais devagar que as outras pessoas, ou tenho que parar para } \\
\text { descansar }\end{array}$ & $\square$ & $\square$ \\
\hline $\begin{array}{l}\text { Demoro muito tempo para realizar as tarefas como o trabalho de casa, } \\
\text { ou tenho que parar para descansar }\end{array}$ & $\square$ & $\square$ \\
\hline $\begin{array}{l}\text { Quando subo um lance de escada, vou muito devagar, ou tenho que } \\
\text { parar para descansar }\end{array}$ & $\square$ & $\square$ \\
\hline $\begin{array}{l}\text { Se estou apressado ou caminho mais depressa, tenho que parar para } \\
\text { descansar ou ir mais devagar }\end{array}$ & $\square$ & $\square$ \\
\hline $\begin{array}{l}\text { Por causa da minha respiração, tenho dificuldades para desenvolver } \\
\text { atividades como: subir ladeiras, carregar objetos subindo escadas, }\end{array}$ & $\square$ & $\square$ \\
\hline
\end{tabular}


dançar, praticar esporte leve

Por causa da minha respiração, tenho dificuldades para desenvolver atividades como: carregar grandes pesos, fazer "Cooper" ou nadar Por causa da minha respiração, tenho dificuldades para desenvolver atividades como: trabalho manual pesado, correr, andar de bicicleta, nadar rápido ou praticar esportes de competição

\section{- Seção 7}

A. Assinale com um "x" o quadrado de cada questão abaixo, indicando resposta Sim ou Não para indicar outras atividades que geralmente podem ser afetadas pela sua doença respiratória:

\begin{tabular}{|l|c|c|}
\hline & Sim & Não \\
\hline Praticar esportes ou jogos que impliquem esforço físico & $\square$ & $\square$ \\
\hline Sair de casa para me divertir & $\square$ & $\square$ \\
\hline Sair de casa para fazer compras & $\square$ & $\square$ \\
\hline Fazer o trabalho de casa & $\square$ & $\square$ \\
\hline Sair da cama ou da cadeira & $\square$ & $\square$ \\
\hline
\end{tabular}

B. A lista seguinte descreve uma séria de outras atividades que o problema respiratório pode impedir você de realizar.

Dar passeios a pé ou passear com o seu cão

Fazer o trabalho doméstico ou jardinagem

Ter relações sexuais

Ir à igreja, bar ou a locais de diversão

Sair com mau tempo ou permanecer em locais com fumaça de cigarro

Visitar a família e os amigos ou brincar com as crianças

Por favor, escreva qualquer outra atividade importante que seu problema respiratório pode impedi-lo de fazer.

C. Das questões abaixo relacionadas, assinale somente aquela que melhor define a forma como você é afetado pela sua doença respiratória:

Não me impede de fazer nenhuma das coisas que eu gostaria de fazer Impede-me de fazer uma ou duas ou duas coisas que eu gostaria de fazer Impede-me de fazer a maioria das coisas que eu gostaria de fazer Impede-me de fazer tudo que eu gostaria de fazer 
Anexo E - LISTA DE COMORBIDADES

Lista de Comorbidades de acordo com o Índice de Charlson

\begin{tabular}{|c|c|c|c|c|}
\hline COMORBIDADES & $P E S O(1)$ & $P E S O(2)$ & $P E S O(3)$ & $P E S O(6)$ \\
\hline Infarto do miocárdio & $\mathrm{x}$ & & & \\
\hline ICC & $\mathrm{x}$ & & & \\
\hline Doença cerebrovascular & $\mathrm{x}$ & & & \\
\hline Doença pulmonar crônica & $\mathrm{x}$ & & & \\
\hline Doença do tecido conjuntivo & $0 x$ & & & \\
\hline Úlcera péptica & $\mathrm{x}$ & & & \\
\hline Doenças do fígado & $\mathrm{x}$ & & & \\
\hline Diabetes & $\mathrm{x}$ & & & \\
\hline Hemiplegia & & $\mathrm{x}$ & & \\
\hline Doença renal (moderada-gra & ave) & $\mathrm{x}$ & & \\
\hline Diabetes com prejuízo orgân & nico & $\mathrm{x}$ & & \\
\hline Algum tumor & & $\mathrm{x}$ & & \\
\hline Leucemia & & $\mathrm{x}$ & & \\
\hline Linfoma & & $\mathrm{x}$ & & \\
\hline Doenças do fígado (moderad & da-grave) & & $\mathrm{x}$ & \\
\hline Tumor sólido metastático & & & & $\mathrm{x}$ \\
\hline AIDS & & & & $\mathrm{x}$ \\
\hline
\end{tabular}


Apêndice A - ROTEIRO DAS LIGAÇÕES

Exacerbação da doença: presença de dois ou mais sintomas e pelo menos uma mudança no tratamento de manutenção

Sintomas (presentes durante três ou mais dias):

- Dispneia

- Aumento do volume do escarro

- Mudança da coloração do catarro

- Tosse

- Chiado

- Dor torácica

Tratamento:

- Uso de antibiótico e/ou corticoide sistêmico

- Uma mudança significativa na prescrição da medicação respiratória

Exacerbação: ( ) sim （ ) não

Sintomas:

Tratamento:

Total de exacerbações:

Hospitalização: ( ) sim ( ) não

Causa:

Óbito: ( ) $\operatorname{sim}$ ( ) não

Causa: 


\title{
Apêndice B - TERMO DE CONSENTIMENTO LIVRE E ESCLARECIDO
}

\author{
Título da pesquisa: \\ "Evolução dos marcadores diagnósticos e prognósticos de pacientes com DPOC no \\ período de três anos"
}

O objetivo deste estudo será avaliar a evolução dos pacientes com Doença Pulmonar Obstrutiva Crônica (DPOC), conhecida como Bronquite Crônica e Enfisema Pulmonar. O (a) Senhor (a) é portador desta doença e foi avaliado e acompanhado por um ano no estudo que avaliou a influência do índice que inclui o peso, a obstrução das vias aéreas, a capacidade para caminhar e a intensidade da falta de ar na ocorrência de exacerbação. No estudo atual, está sendo convidado a realizar uma segunda avaliação que incluirá o estudo de seu pulmão, da intensidade da falta de ar, da qualidade de vida, do estado nutricional e da capacidade para caminhar.

Você terá seu peso e estatura medidos e deverá caminhar, sob supervisão, durante 6 minutos. Será submetido à coleta de sangue arterial para verificar seus gases sanguíneos (a quantidade de oxigênio no sangue). Esses exames são regularmente utilizados em pacientes com DPOC e o (a) Senhor (a) já realizou todos eles no estudo anterior. Em caso de alguma complicação nos exames, o Senhor (a) será encaminhado para tratamento adequado.

Os riscos associados aos procedimentos utilizados na realização do estudo são mínimos. $\mathrm{O}$ estudo não envolve qualquer alteração nos tratamentos que esteja recebendo e as suas informações e dados pessoais serão utilizados apenas em reuniões de caráter científico e serão mantidos em sigilo profissional. Qualquer dúvida em relação ao estudo será imediatamente esclarecida e o (a) Senhor (a) estará livre para retirar seu consentimento e desistir de participar do estudo, em qualquer momento, sem interferência no tratamento que recebe na instituição. Ao entrar nesse estudo, sua identidade não será revelada. $\mathrm{Eu}$ entendo o que foi descrito acima e dou meu consentimento para ser incluído neste estudo.

\section{Assinatura do participante}

Eu declaro que expliquei ao participante acima a natureza e os objetivos da pesquisa, os prováveis benefícios e possíveis riscos com a participação neste estudo. Este documento será elaborado em 2 vias, sendo uma entregue ao participante e outra será mantida em arquivo.

Pesquisadora: Renata Ferrari

Assinatura da pesquisa

Rua: João Vieira de Mello, 251- Botucatu - SP

Fone: (14) 38116213

E-mail: renataferrarifisio@gmail.com

Orientadora: Prof ${ }^{a}$ Adjunta Irma de Godoy

Disciplina de Pneumologia/ Departamento de Clínica Médica

Faculdade de Medicina de Botucatu

Fone: (14)3882-2969 ou 38823822 - E-mail: irma@ fmb.unesp.br 